\title{
Evolution of Salmonella-Host Cell Interactions through a Dynamic Bacterial Genome
}

\author{
Bushra llyas ${ }^{1,2}$, Caressa N. Tsai ${ }^{1,2}$ and Brian K. Coombes ${ }^{2 *}$ \\ ${ }^{1}$ Department of Biochemistry and Biomedical Sciences, McMaster University, Hamilton, ON, Canada, ${ }^{2}$ Michael DeGroote \\ Institute for Infectious Disease Research, McMaster University, Hamilton, ON, Canada
}

Salmonella Typhimurium has a broad arsenal of genes that are tightly regulated and coordinated to facilitate adaptation to the various host environments it colonizes. The genome of Salmonella Typhimurium has undergone multiple gene acquisition events and has accrued changes in non-coding DNA that have undergone selection by regulatory evolution. Together, at least 17 horizontally acquired pathogenicity islands (SPIs), prophage-associated genes, and changes in core genome regulation contribute to the virulence program of Salmonella. Here, we review the latest understanding of these elements and their contributions to pathogenesis, emphasizing the regulatory circuitry that controls niche-specific gene expression. In addition to an overview of the importance of SPI-1 and SPI-2 to host invasion and colonization, we describe the recently characterized contributions of other SPIs, including the antibacterial activity of SPI-6 and adhesion and invasion mediated by SPI-4. We further discuss how these fitness traits have been integrated into the regulatory circuitry of the bacterial cell through

OPEN ACCESS

Edited by:

Ariel Blocker,

University of Bristol, United Kingdom

Reviewed by:

Andres Vazquez-Torres, University of Colorado Denver, United States

Jose L. Puente, National Autonomous University of Mexico, Mexico

*Correspondence:

Brian K. Coombes coombes@mcmaster.ca

Received: 21 June 2017 Accepted: 19 September 2017 Published: 29 September 2017

Citation:

Ilyas B, Tsai CN and Coombes BK (2017) Evolution of Salmonella-Host Cell Interactions through a Dynamic Bacterial Genome. Front. Cell. Infect. Microbiol. 7:428. doi: 10.3389/fcimb.2017.00428 cis-regulatory evolution and by a careful balance of silencing and counter-silencing by regulatory proteins. Detailed understanding of regulatory evolution within Salmonella is uncovering novel aspects of infection biology that relate to host-pathogen interactions and evasion of host immunity.

Keywords: Salmonella infection biology, bacterial pathogenesis, horizontal gene transfer, regulatory evolution, virulence regulation, gene loss, comparative genomics, xenogeneic silencing

\section{INTRODUCTION}

Salmonella is a genus of enteric pathogens that consists of two species, Salmonella enterica and Salmonella bongori, which can cause disease in a broad range of hosts. S. bongori is predominantly associated with infection in reptiles, although it has been isolated in human infections (Nastasi et al., 1988; Giammanco et al., 2002). S. enterica is further divided into seven subspecies, which can cause gastroenteritis or systemic disease in a variety of warm- and cold-blooded animals (McQuiston et al., 2008). Among the S. enterica subspecies, S. enterica subsp. enterica is the only one that can infect mammals, and is associated with human disease. This subspecies includes host-restricted serovars like Salmonella Typhi, which causes typhoid fever in humans, and the broad host-range Salmonella Typhimurium, which causes gastroenteritis in humans and other mammals (Uzzau et al., 2000). The evolution of Salmonella as a pathogen has been broadly studied over the past few decades. The recent rise in comparative genomics methods has cast a light on the molecular basis of pathogenesis, revealing that the evolution of Salmonella toward pathogenicity was mediated by several horizontal transfer events (Bäumler, 1997; Groisman and Ochman, 1997). 
Genes acquired by horizontal transfer can confer new phenotypes to the recipient bacteria and are often the source of adaptive changes that maximize fitness in a given niche (Ochman et al., 2000). In the Salmonella genomics vernacular, horizontally acquired multi-gene loci linked to infection are called Salmonella Pathogenicity Islands (SPIs), and have been described as the "molecular toolbox" for Salmonella pathogenesis (Gal-Mor and Finlay, 2006). The SPI pan-genome includes 21 SPIs, most of which are present in both species, and across all subspecies (McClelland et al., 2001). However, there is genetic flux with the Salmonella species and subspecies, which define host range and disease phenotype (Bäumler, 1997; Fookes et al., 2011).

Perhaps the best-studied serovar of Salmonella is $S$. enterica subsp. enterica sv. Typhimurium (S. Typhimurium). $S$. Typhimurium is amenable to molecular manipulation, can infect numerous cell types, and robust animal models have been developed to model both self-limiting gastroenteritis and systemic infection (Finlay and Brumell, 2000; Tsolis et al., 2011). Together, these tools have laid the foundation for understanding the genetic basis for Salmonella virulence, and have helped understand the host response to infection. The contributions of SPI-1 and 2 to Salmonella pathogenicity have been reviewed in detail several times (Hensel, 2000; Wallis and Galyov, 2000; Waterman and Holden, 2003; Haraga et al., 2008), and more recent attention has been directed toward the evolution and virulence determinants of the other SPIs (Morgan et al., 2004; Haneda et al., 2009; Nieto et al., 2016). In this review, we highlight the contribution of horizontally acquired genes to the adaptation of Salmonella as a pathogen and its biology within host cells. Further, because many bacteria share a conserved repertoire of core genes, we discuss a notion that uncovering selective changes to gene deployment via regulatory evolution among conserved genes is a strategy to uncover novel aspects of infection biology.

\section{DISTINCT VIRULENCE FACTORS DRIVE SPECIFIC STAGES OF SALMONELLA INFECTION}

Genetically susceptible mice (Nramp/SLC11A1 $\left.{ }^{-/-}\right)$orally infected with $S$. Typhimurium develop systemic disease, characterized by high bacterial burdens in the spleen and liver, gross intestinal pathology, and death from systemic bacteremia (Santos et al., 2001; Cuellar-Mata et al., 2002). Streptomycin pretreatment in this model lowers intrinsic colonization resistance and intensifies the bacterial-driven intestinal inflammation, a finding that has been extensively leveraged to understand how Salmonella competes metabolically in the inflamed intestine (Barthel et al., 2003; Winter et al., 2010a,b). During the infection process, $S$. Typhimurium invades epithelial cells or is taken up by $\mathrm{M}$ cells, colonizes the Peyer's patches and associated lymphoid tissue, and invades or is phagocytosed by immune cells such as macrophages and neutrophils. In this permissive niche for replication, systemic dissemination proceeds to shuttle salmonellae to sites such as the spleen and liver. At each step in this process, specific virulence factors (summarized in Table 1) are activated to interact with the host to make the environment more conducive to bacterial survival and replication. Below, we describe the three major stages of Salmonella infection and the genetic basis for pathogenesis at each one (Figure 1).

TABLE 1 | Summary of horizontally acquired genes and their role in Salmonella interaction with host cells.

\begin{tabular}{|c|c|c|c|}
\hline Virulence factor & Gene location & Activity & Role in infection \\
\hline SipA, SipB & SPI-1 & Actin binding & Membrane ruffling, invasion (Raffatellu et al., 2005) \\
\hline SseF, SseG & SPI-2 & Interacts with microtubules & SCV localization, intracellular survival (Hensel et al., 1998) \\
\hline MisL & SPI-3 & Binding fibronectin & Attachment, long term colonization (Dorsey et al., 2005) \\
\hline SiiE & SPI-4 & Adhesion to epithelial cells & Attachment to intestinal epithelium, aids in invasion (Morgan et al., 2007) \\
\hline SopB & SPI-5 & Interaction with Rho-GTPase & $\begin{array}{l}\text { Membrane ruffling, invasion of epithelial cells, activation of pro-inflammatory } \\
\text { response (Perrett and Zhou, 2013) }\end{array}$ \\
\hline Tae4 & SPI-6 & Anti-bacterial type 6 & Overcoming colonization resistance, luminal colonization (Sana et al., 2016) \\
\hline SciG, SciS & SPI-6 & Unknown & Intracellular survival, systemic infection (Mulder et al., 2012) \\
\hline $\begin{array}{l}\text { PagC, PagD, } \\
\text { EnvE, EnvF }\end{array}$ & SPI-11 & $\begin{array}{l}\text { Salmonella outer membrane } \\
\text { remodeling }\end{array}$ & $\begin{array}{l}\text { Resistance to antimicrobial peptides, survival within macrophages (Miller } \\
\text { et al., 1989; Gunn et al., 1995) }\end{array}$ \\
\hline $\mathrm{SspH} 2$ & SPI-12 & Interaction with NLR's & Immune evasion, intracellular survival (McGhie et al., 2009) \\
\hline $\begin{array}{l}\text { STM3118, } \\
\text { STM3119 }\end{array}$ & SPI-13 & $\begin{array}{l}\text { Peptidoglycan remodeling, } \\
\text { putative monoamine oxidase }\end{array}$ & Immune evasion, survival within macrophages (Haneda et al., 2009) \\
\hline LoiA & SPI-14 & Regulation of hilD on SPI-1 & Regulation of SPI-1 genes, important for invasion (Jiang et al., 2017) \\
\hline STM0557 & SPI-16 & O-antigen modification & Serotype conversion, long term colonization (Bogomolnaya et al., 2008) \\
\hline SopE & $\begin{array}{l}\text { SopE } \Phi \text { prophage, present in subset } \\
\text { of } S \text {. Typhimurium isolates }\end{array}$ & Interaction with caspase-1 & iNOS activation, luminal colonization (Mirold et al., 2001; Lopez et al., 2012) \\
\hline GogB & Gifsy-1 & Interaction with ubiquitin ligase & $\begin{array}{l}\text { Inhibition of pro-inflammatory response, survival within macrophages (Pilar } \\
\text { et al., 2012) }\end{array}$ \\
\hline SodC & Gifsy-2 phage, Fels-1 phage & Superoxide dismutase & Resistance to oxidative stress, survival within SCV (Ehrbar and Hardt, 2005) \\
\hline SspH1 & $\begin{array}{l}\text { Gifsy- } 3 \text { phage, present in subset of } \\
\text { S. Typhimurium isolates }\end{array}$ & Ubiquitin protein ligase & $\begin{array}{l}\text { Immune suppression, survival within SCV (Ehrbar and Hardt, 2005; Haraga } \\
\text { and Miller, 2006) }\end{array}$ \\
\hline
\end{tabular}




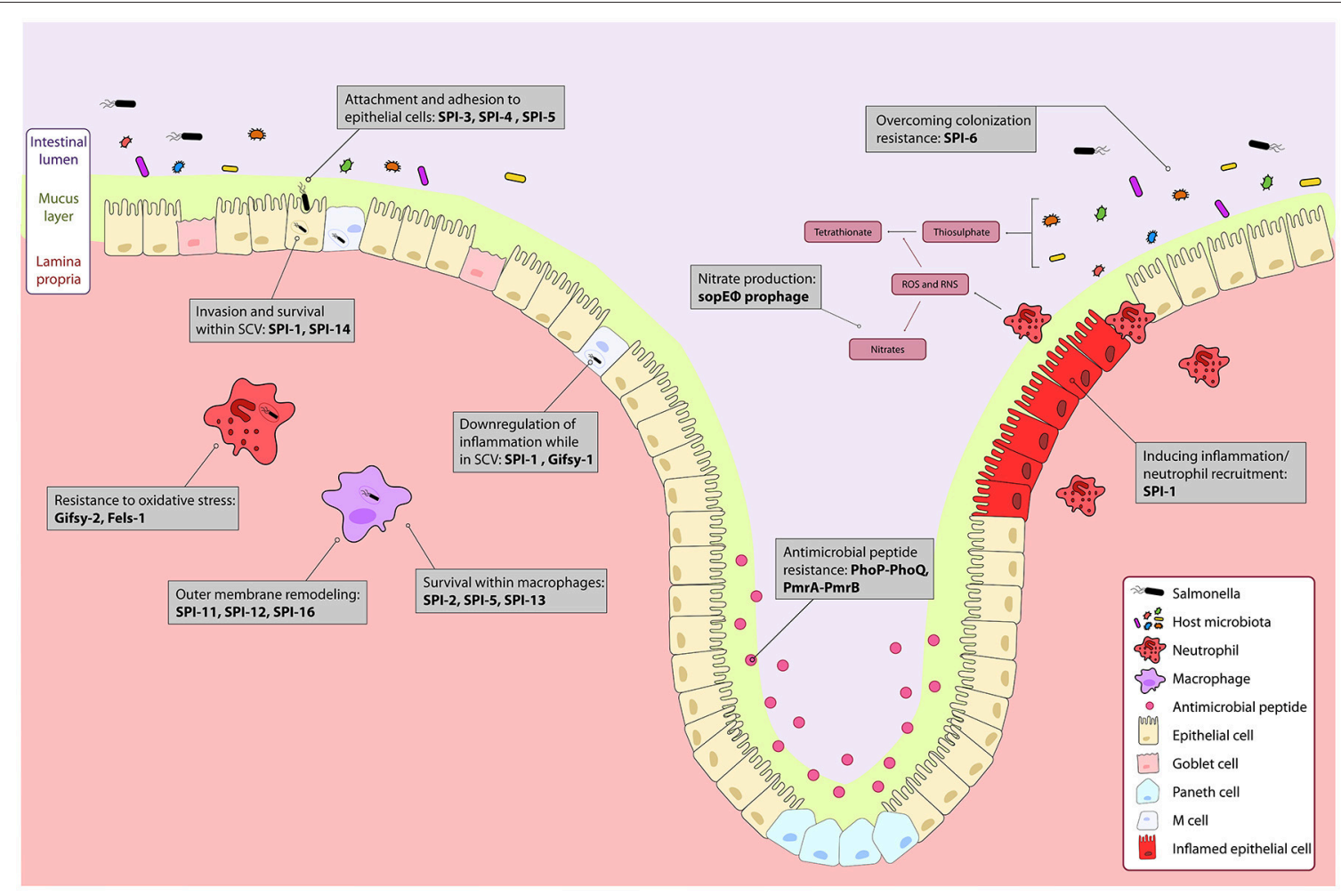

FIGURE 1 | The course of Salmonella infection within the intestine is driven by horizontally acquired virulence factors. Genes encoded on the horizontally acquired Salmonella Pathogenicity Islands (SPIs) and prophage associated genes are important during Salmonella infection of the intestine. Salmonella colonizes the intestinal lumen through activation of robust inflammation by genes encoded on the sopE prophage, and SPI-1 secreted effectors, and outcompetes commensal microbes metabolically, and with a type 6 secretion system encoded on SPI-6. The PhoPQ and PmrAB two-component systems regulate resistance to luminal antimicrobial peptides. Surface proteins encoded on SPI-3 and SPI-4 drive attachment to epithelial cells, and bacterial mediated endocytosis into epithelial cells is induced by gene products from SPI-1 and SPI-5. Modification of the bacterial endosome and survival within the Salmonella containing vacuole (SCV) is driven by SPI-1 and the Gifsy-1 prophage. Within the SCV and in immune cells like neutrophils and macrophages, resistance to immune responses such as oxidative stress is mediated by the Gifsy-2 and Fels-1 prophages, and SPI-11, SPI-12, and SPI-16 that remodel the outer membrane to evade immune responses. Survival within macrophages is mediated by SPI-2, SPI-5, SPI-13. Together, these genes allow for colonization and systemic infection of Salmonella Typhimurium.

\section{Luminal Colonization}

Following oral inoculation of mice, Salmonella face the challenge of colonizing the intestinal lumen prior to invasion and dissemination to systemic sites. An uncontrived gut microbiota limits nutrient availability and provides colonization resistance toward this first infection step (Patel and McCormick, 2014; Erhardt and Dersch, 2015). Considerable research has investigated how Salmonella overcomes such host restrictions within the intestinal lumen, revealing a key role for horizontally acquired genes in endowing Salmonella with the ability to outcompete commensal microbes to establish an intestinal niche. A recent study identified direct killing of commensal microbes by Salmonella through the expression of a type 6 secretion system (T6SS), a widely-distributed nano-machine used primarily for inter-bacterial antagonism (Sana et al., 2016). The Salmonella T6SS, encoded on the horizontally acquired island SPI-6-formerly Salmonella centisome 7 genomic island (SCI 7; Blondel et al., 2009)-encodes an antibacterial amidase (Tae4) that can induce bacterial lysis in non-immune target cells (Sana et al., 2016). This ability seems to confer a fitness benefit to Salmonella at later stages of colonization of the gut lumen, but not systemic sites of infection (Sana et al., 2016, 2017). Interestingly, accessory genes within the SPI-6 island also contribute to intracellular replication and systemic dissemination in the permissive mouse line, C57BL/6 (Mulder et al., 2012). These data suggest that in addition to a role in antibacterial antagonism in the gut, the Salmonella T6SS appears to also have a secondary role in an unknown facet of intracellular cell biology. In other bacteria, the T6SS is involved in dampening host immunity (Chen et al., 2017), promoting intracellular growth in macrophages (Eshraghi et al., 2016), and interacting with the host microtubule network (Sana et al., 2015), all of which point to an expanding role for T6SS in host-pathogen interactions.

Induction of inflammation is another host defense mounted in response to Salmonella in the lumen. Surface proteins on Salmonella, like flagellin and LPS, are detected by pattern recognition receptors (PRRs) on epithelial and immune cells to activate innate immune responses (Gewirtz et al., 2001). This proinflammatory environment is associated with a rapid neutrophil 
influx, leading to induction of oxidative and nitrosative stress that targets both pathogenic and commensal bacteria in the lumen (Tükel et al., 2006). Salmonella actively induces intestinal inflammation, and this inflammatory response is important for successful luminal colonization (Stecher et al., 2007). One of the key mediators of this intestinal inflammation are the gene products of the Salmonella pathogenicity island 1 (SPI-1; Lee et al., 2000). This island encodes a type 3 secretion system (T3SS-1) that translocates effector proteins into host cells to modulate their function. Effector proteins encoded within SPI1 and in other horizontally acquired islands are translocated through the T3SS-1, and can induce inflammation within the gut. The interaction of the SPI-1 translocated proteins SopB, SopE, and SopE2 with epithelial cell Rho GTPases activates NF-kB and eventually leads to the release of pro-inflammatory cytokines such as IL-1 $\beta$ and IL-23 (Santos et al., 2009). Certain SPI-1 secreted proteins, such as SipC, SipD, and SopE have been shown to induce iNOS expression in macrophages, and recent research has demonstrated that this induction, specifically by SopE, promoted Salmonella colonization (Cherayil et al., 2000; Lopez et al., 2012). The mechanistic basis for the enhanced growth of Salmonella in the inflamed gut appears to be largely metabolic fitness. Much work has demonstrated that Salmonella thrives in inflamed environments because it can better utilize metabolic byproducts generated during inflammation. For example, nitrates produced from reactive oxygen and nitrogen products within the lumen, and tetrathionate produced from reduced thiosulfate, provide alternative energy sources for Salmonella, which can be metabolized in the anaerobic gut environment (Winter et al., 2010b; Lopez et al., 2012). Salmonella-specific genes such as the tetrathionate utilization operon $(t t r)$ allow the bacteria to utilize these alternate metabolites to outcompete commensal microbes (Hensel et al., 1999; Rivera-Chávez et al., 2013). Although nitrate respiration is conserved among Proteobacteria, the existence of a secretion system effector that manipulates the host in order to preferentially generate nitrates has only been reported in Salmonella (Lopez et al., 2012). In addition to the metabolic benefits of oxidative and nitrosative stress, Salmonella encodes redundant systems of defense against these reactive oxygen and nitrogen intermediates, acting to mitigate damage under high concentrations (Vazquez-Torres et al., 2000; Aussel et al., 2011; Henard and Vázquez-Torres, 2011).

Within the lumen, salmonellae also encounter antimicrobial peptides secreted by epithelial cells and infiltrating immune cells, which work to disrupt membrane integrity (Bevins and Salzman, 2011). Salmonella has a number of genes that modify the outer membrane to protect against this host defense activity. Many of these genes are regulated by the PhoPQ and PmrAB two-component systems (Gunn and Miller, 1996). Horizontally acquired genes have also been implicated in the defense to antimicrobial peptides. For example, Salmonella can inhibit antimicrobial peptide production by Paneth cells in a T3SS-1-dependent manner (Salzman et al., 2003). This is likely mediated through the modification of host cell signaling pathways induced by SPI-1 effector proteins.

\section{Invasion of Epithelial Cells Is a Cooperative Multi-gene Process}

The attachment and invasion of Salmonella to host epithelial cells sets up conditions that eventually favor luminal colonization and systemic infection. Epithelial cells in the gut, specifically goblet cells, produce mucins that form a physical barrier between the apical surface of these cells and the lumen (McGuckin et al., 2011). Zarepour et al. showed that this mucus barrier is an important host defense against Salmonella (Zarepour et al., 2013). Virulent Salmonella strains can bind to mucin preparations better than avirulent strains, suggesting the genetic factors involved in Salmonella virulence mediate this binding, although the interacting partners have not been identified (Vimal et al., 2000). As Salmonella approaches the epithelial barrier within the intestine, it can be endocytosed by M cells (Clark et al., 1994). Entry into the lamina propria allows for TLR activation by flagellin on the basolateral surface, uptake by macrophages, and activation of $\mathrm{B}$ and $\mathrm{T}$ cells (Johansson et al., 2006). In addition to luminal sampling by $\mathrm{M}$ cells, Salmonella can mediate uptake by host epithelial cells through a cooperative interaction among several virulence factors. Genes on SPI-4, which encode a Type 1 secretion system and major adhesin protein SiiE, are important for initiating epithelial cell contact in the intestine (Gerlach et al., 2007). The activity of SiiE is important for maximal bacterial entry into polarized epithelial cells because it allows for clusters of bacteria in close proximity to the invasion site to be pulled into the membrane ruffle at the host cell surface (Lorkowski et al., 2014). In addition to SiiE in SPI-4, the horizontally acquired gene misL, encoded on SPI-3, binds fibronectin and is required for long-term colonization (Dorsey et al., 2005). Along with the protein ShdA, which is not encoded on a genomic island, binding to surface structures like fibronectin appears to be important for intestinal persistence (Kolachala et al., 2007). The activation of intestinal inflammation can increase levels of fibronectin on epithelial cells, and MisL has been suggested to bind fibronectin at areas of epithelial cell erosion, thus providing another example of the link between intestinal inflammation and efficient bacterial invasion.

The T3SS-1-mediated invasion of Salmonella has been extremely well-studied and the specific role of SPI-1 associated effectors in this process have been reviewed elsewhere (Lostroh and Lee, 2001; McGhie et al., 2009; Que et al., 2013). The net result of effector translocation upon host cell contact is the induction of major cytoskeletal changes in the epithelial cell, leading to membrane ruffling and bacterial internalization. The effectors involved in this process are encoded in SPI-1 and elsewhere in the genome and are coordinated at the level of gene regulation for synchronized expression. Novel functions and regulatory interactions are still being uncovered for even wellknown SPI-1 effectors. For example, the phage-encoded effector, SopE, can exert an inside-out response on host epithelial cells by enhancing their expression of iNOS, which in turn liberates hostderived nitrate that luminal Salmonella can respire anaerobically (Lopez et al., 2012). The SPI-5 genomic island is another mosaic island that enables different stages of the Salmonella infection process. The SPI-5 effector, SopB, is expressed and translocated by the T3SS-1 early in infection to promote membrane ruffling 
and invasion, whereas PipB (also encoded in SPI-5), is activated when Salmonella is within host cells and is translocated by the SPI-2-encoded type 3 secretion system (T3SS-2) to promote intra-macrophage survival (Knodler et al., 2002). Recently, SPI14 was identified as being involved in Salmonella virulence by mediation of bacterial invasion, however the gene responsible appears to play a role in the activation of SPI-1 genes, rather than directly interacting with host processes (Jiang et al., 2017).

Shortly after bacterial invasion, effectors secreted by SPI1 control reversion of the host epithelial cell to its normal state, inducing de-ruffling of the membrane and repression of the pro-inflammatory signals. This is typically mediated by host ubiquitination pathways that target SPI-1 effector proteins for degradation. However, there are also specific effectors secreted through SPI-1 that modify the Salmonella containing vacuole (SCV). For example, the phage-encoded effector SspH2, translocated by SPI-1, helps to down-regulate pro-inflammatory responses once Salmonella is in the SCV (McGhie et al., 2009). SPI-1 effectors can recruit host factors to the vacuolar membrane to redirect the vacuole in the endosomal trafficking pathway, thus limiting lysosomal fusion. SPI-1 associated genes are also implicated in escape from the SCV in non-phagocytic cells, allowing for Salmonella survival and replication in the cytosolic compartment. This has been recently characterized in a number of epithelial cell lines (Knodler et al., 2010, 2014). The hyperreplication seen in the cytosol is associated with Salmonella induced pyroptosis of host cells, releasing primed bacteria into the lumen where they can infect other cells, or be picked up by macrophages. A subset of SCV's are subject to destabilization by SPI-1 associated genes, leading to a dual lifestyle of Salmonella within epithelial cells (Knodler, 2015).

\section{Salmonella Survival within Host Immune Cells}

Whether through bacterial mediated pyroptosis, trafficking of the SCV to the basolateral surface of epithelial cells, or by direct sampling of luminal bacteria by dendritic cells, Salmonella eventually arrives in the lamina propria where it is taken up by phagocytic cells through a combination of bacterialmediated endocytosis and immune cell driven phagocytosis (Haraga et al., 2008). Within immune cells, several horizontally acquired virulence determinants are deployed in the creation of the SCV and the evasion of host immune defenses. The virulence genes necessary for bacterial survival within macrophages are predominantly located on the SPI-2 genomic island that encodes the T3SS-2 and two translocated effectors, SseF and SseG (Ochman et al., 1996; Shea et al., 1996). We will not review these genes in detail as they have been comprehensively reviewed elsewhere (Cirillo et al., 1998; Hensel et al., 1998; Haraga et al., 2008; Figueira and Holden, 2012). However, a number of phage associated genes and genes encoded on other genomic islands are paramount to the survival of Salmonella within macrophages. For example, SPI-12 encodes sspH2, which is secreted by the T3SS-2. SPI-12 is a pathogenicity island relevant for immune evasion that was first linked to virulence in a calf model of $S$. Typhimurium infection (Hansen-Wester and Hensel,
2001, 2002). Transcription of the sspH2 gene is induced in an SsrB-dependent manner during survival within RAW264.7 macrophages, and sspH2 mutants do not induce lethal infection of calves (Miao et al., 1999; Tomljenovic-Berube et al., 2013). Also present within SPI-12 is oafA, which acetylates O-antigen on its 2-hydroxyl group to generate the O5 serotype, which confers antigenic variation beneficial for pathogenesis and immune evasion (Slauch et al., 1996). Similarly, SPI-5 encodes pipA, another effector translocated by SPI-2 that if deleted, reduces virulence in a mouse infection (Knodler et al., 2002).

The importance of bacteriophages to the spread of virulence determinants through horizontal gene transfer is well-established (Barksdale and Arden, 1974; Cheetham and Katz, 1995; Waldor, 1998). In line with this, several pathogenicity islands in the Salmonella genome are proximal to either phage-encoding genes or phage attachment sites (Blanc-Potard and Groisman, 1997; Wood et al., 1998). Of pathogenic importance are two prophagelike genomic regions harbored within S. Typhimurium, Gifsy1 and 2. Both of these genetic elements influence the interactions of Salmonella with host cells, as was identified due to their transcriptional induction upon exposure to reactive oxygen species. Notably, Gifsy-2 encodes the sodC periplasmic superoxide dismutase that confers resistance to oxidative stress (Figueroa-Bossi and Bossi, 1999). Variants of S. Typhimurium that are cured of these prophage become rapidly re-lysogenized upon exposure to hydrogen peroxide, indicating the importance of these genetic elements for pathogenesis and survival in vivo (Figueroa-Bossi and Bossi, 1999; Figueroa-Bossi et al., 2001). The Gifsy-1 prophage encodes $\operatorname{gog} B$, an effector that can be translocated by both SPI-1 and 2 (Coombes et al., 2005a). GogB targets the host SCF E3 type ubiquitin ligase through an interaction with Skp1 and the human F-box only 22 (FBXO22) protein to inhibit the pro-inflammatory response once Salmonella is in the intracellular niche (Pilar et al., 2012). Another phage relevant for infection is Fels-1, which carries a third sodC gene, again contributing to the resistance response to oxidative stress (Brüssow et al., 2004).

Within the macrophage environment, both sequestration of essential metals as well the fusion of granules containing antimicrobial peptides to the SCV act together to restrict bacterial replication. SPI-11 encodes several genes that are critical for pathogenesis and survival at this stage of infection (Miller et al., 1989). This pathogenicity island is present in both the Typhimurium and Typhi serovars, however it has undergone degradation to some extent within Typhimurium. Of particular importance are a set of genes that encode the envelope proteins, pagD, envE, envF (Gunn et al., 1995). These genes participate in outer membrane remodeling that improves resistance to the immune defenses encountered intracellularly. Additional important SPI-11 genes are $p a g C$ and $p a g D$, which are part of the PhoPQ regulon and were likely acquired via horizontal gene transfer (Gunn et al., 1995). Transposon insertions within these genes have been shown to attenuate virulence and restrict survival within macrophages (Miller et al., 1989).

The systemic spread of Salmonella to the liver and spleen is contingent upon survival within the macrophage environment; mutants in Salmonella that cannot survive within 
this environment are avirulent in a systemic mouse model of infection. Salmonella-containing macrophages enter the mesenteric lymph node, where they are shuttled to the liver and spleen (Watson and Holden, 2010). Replication within macrophages is also essential for colonization at the liver and spleen, as analyses of cell types within these tissues containing Salmonella identify macrophages, and to a degree neutrophils, as the primary cells at infection foci (Geddes et al., 2007; Thöne et al., 2007). Genes encoded on SPI-13 are important for intracellular viability (Shi et al., 2006). SPI-13 contains a cluster that encodes putative lyase, hydrolase, oxidase, arylsulphatase regulators, and deletion of this island renders Salmonella attenuated for virulence (Haneda et al., 2009). STM3118 (a homolog of acetyl-coA hydrolase) is an important virulence factor contained within this island that hydrolyzes acetyl-coA to acetate in order to modify peptidoglycan as a protective mechanism against degradative enzymes found in macrophages. Additionally encoded in SPI-13 is STM3119, a monoamine oxidase that converts aminoacetone (degradation product of L-threonine) to a peptidoglycan precursor (Shi et al., 2006). Further characterizing the function of genes encoded on SPI13 is likely to broaden our understanding of how Salmonella modulates the intracellular environment and interacts with the host during systemic infection.

SPI-16 is a pathogenicity island that contributes to immune evasion in the form of $\mathrm{O}$-antigen variation. It includes the gene STM0557 that resembles bactoprenol-linked glucose translocases (for example $g \operatorname{tr} A / B$ ), and is predicted to be involved in serotype conversion through glycosylation of O-antigen. The gtr cluster of genes encodes proteins that add glucose residues to repeating $\mathrm{O}$-antigen subunits within LPS, and ultimately confer form variation at the $\mathrm{O}-12$ antigen galactose to generate the $12-2$ variant. Most commonly, this variant arises after exposure to or growth within macrophages (Bogomolnaya et al., 2008). It has been demonstrated that form variation within $\mathrm{O}$-antigen is critical for persistence of Salmonella infection in the murine intestine, and so SPI-16 may play a role in the re-infection of the intestine from the gall bladder once Salmonella has established a niche in the liver in a chronic model of Salmonella infection.

Taken together, the suite of horizontally acquired virulence genes found across the SPIs act in a concerted fashion to drive infection, as Salmonella successfully outcompetes the host microbiota, colonizes the lumen, invades the intestinal epithelium, and resides within the replicative niches of neutrophils and macrophages. At various stages of the pathogenesis process, Salmonella encounters several host defense mechanisms deployed by the immune system. However, it appears that Salmonella has evolved to integrate these immune response cues into signaling pathways leading to adaptive gene expression that, ultimately, evades these very host defenses (Wong et al., 2009; Arpaia et al., 2011). In severe stages of systemic infection, the establishment of infection foci in the liver and spleen eventually leads to necrotic lesions and death of susceptible mice through lipid A induced toxic shock (García-Del Portillo, 2001; Santos et al., 2001).

\section{REGULATORY EVOLUTION AND TRANSCRIPTIONAL REWIRING IN SALMONELLA}

Horizontal gene transfer drives bacterial evolution by introducing large amounts of genetic variation in single events, giving rise to adaptation occurring in what many refer to as "quantum leaps" (Groisman and Ochman, 1996). However, in order for horizontally acquired genes to confer fitness advantages, their expression is subject to precise regulatory control such that they are deployed at the appropriate times to contribute beneficially to the organism. Here, we describe the regulatory circuitry within Salmonella that has evolved to integrate newly acquired genes into the existing flexible genetic networks that mediate pathogenesis (Figure 2).

\section{H-NS: The Master Silencer of Horizontal Transfer Events}

Although, the acquisition of genes through horizontal transfer has been essential to the evolution of Salmonella pathogenesis, the majority of foreign DNA is detrimental to bacteria (Buckling and Rainey, 2002; Navarre et al., 2007). Insertion within functional genes, overexpression of energetically taxing genes, and activation of unfavorable gene products are all examples of the drawbacks to horizontal gene transfer. Thus, the integration of these genes into core regulatory circuitry is critical for appropriate temporal gene expression and to ensure that these genes do not antagonize existing cellular functions. While this integration slowly proceeds via cisregulatory mutation (discussed later), transcriptional silencing of horizontally acquired genes, termed xenogeneic silencing, protects the bacteria from these laterally acquired genes (Singh et al., 2016).

Seminal work over the past decade has identified H-NS, a DNA binding protein conserved across Gram-negative bacteria, as a broad repressor of horizontally acquired genes (Lucchini et al., 2006; Navarre et al., 2006). The mechanism of this repression relies on the intrinsic curvature of DNA rich in adenine and thymine (AT-rich; Navarre et al., 2006), which allows for $\mathrm{H}$-NS binding in the minor groove, followed by nucleation and bridging along the DNA that ultimately blocks RNA polymerase (Ali et al., 2012). The existence of H-NS as a global sentinel of horizontally acquired genes has been speculated to contribute to the preferential retention of AT-rich horizontally acquired genes, as H-NS can mitigate the immediate harmful effects of lateral gene transfer (Dorman, 2007; Higashi et al., 2016).

Without compensatory mutations, deletion of hns tends to be lethal in Salmonella but not in closely related bacteria like E. coli, indicating the importance of H-NS to the biology and virulence of Salmonella (Navarre et al., 2006; Ali et al., 2014). Given the importance of horizontally acquired genes to the host-adapted lifestyle of Salmonella, research on H-NS has focused on the protein as a regulator of the pathogenic lifestyle. H-NS binds to SPIs 1-6 as well as other virulence-associated 


\section{A Core regulators and horizontally acquired genes: pagC and PhoP/H-NS}

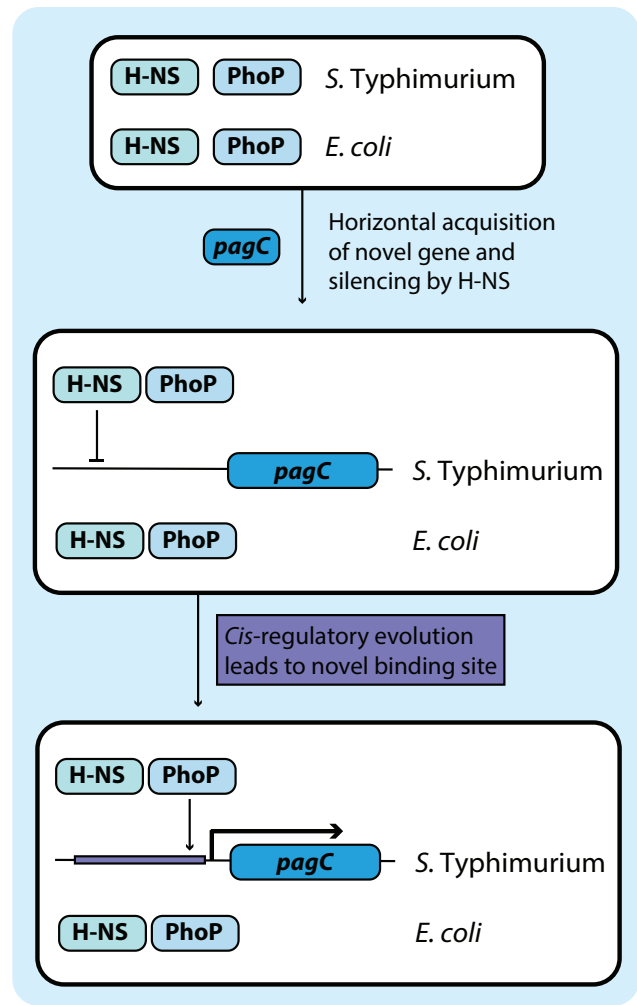

B Horizontally acquired regulators and core genes: srfN and SsrB

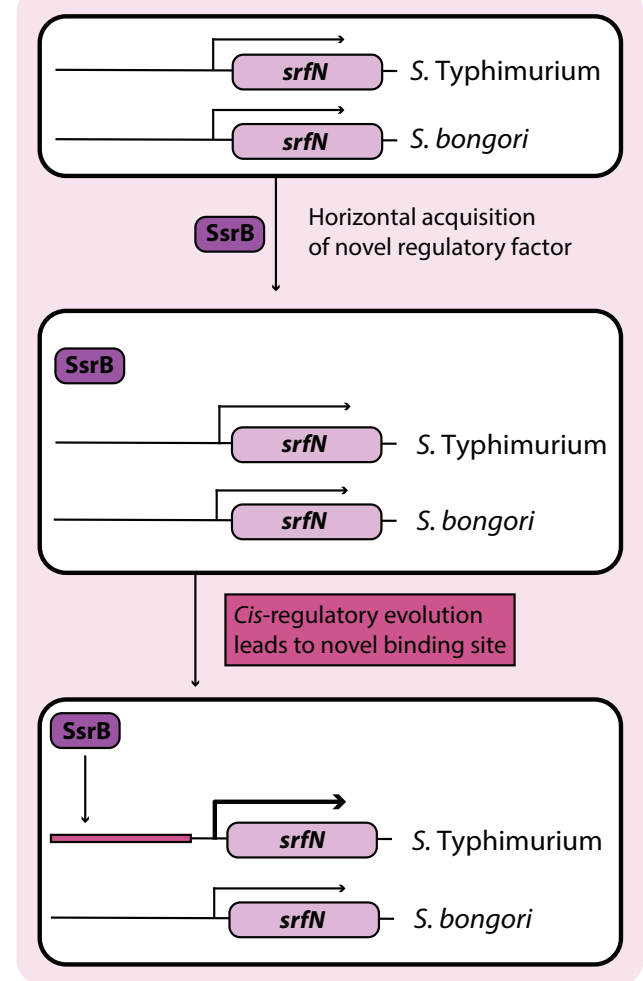

FIGURE 2 | Development of novel regulatory pathways through transcriptional rewiring. (A) Horizontally acquired genes in Salmonella are silenced by H-NS, and cis-regulatory elements can undergo mutations to acquire binding sites that bring these genes under the control of a core virulence regulator such as PhoP. This counter-silencing allows for activation of virulence relevant horizontally acquired genes like pagC in infection relevant conditions. (B) Acquisition of the transcriptional regulator SsrB in Salmonella Typhimurium led to cis-regulatory evolution of core genes that allow them to come under the regulatory control of SsrB. This regulatory rewiring of core genes fine-tunes their expression under infection conditions with other SsrB regulated genes.

islets, blocking RNA polymerase from activating transcription from these loci (Stoebel et al., 2008). The importance of $\mathrm{H}-\mathrm{NS}$ in pathoadaptation is further highlighted in in vitro evolution experiments, where mutations in hns are associated with loss of virulence determinants such as SPI-1 (Ali et al., 2014).

While H-NS is the most widely known silencer of virulence gene expression, it does not act alone upon horizontally acquired genes. Co-factors such as Hha and YdgT, and other nucleoid associated proteins like Fis contribute to the expression of horizontally acquired genes in Salmonella, including those that regulate virulence (Schechter et al., 2003; Silphaduang et al., 2007; Vivero et al., 2008). In contrast with core genes, which can be silenced by H-NS alone, the silencing of horizontally acquired genes such as those on the SPI loci or the PSLT plasmid additionally involve the co-factors Hha and YdgT (Vivero et al., 2008). Hha is specific to enteric bacteria and YdgT is specific to E. coli and Salmonella, yet are both involved in stabilizing $\mathrm{H}-\mathrm{NS}$ at horizontally acquired promoters by mediating additional DNA contacts and allowing for $\mathrm{H}-\mathrm{NS}$ aggregation (Coombes et al., 2005b; Ali et al., 2014). Similar to
H-NS, the expression of Hha facilitates acquisition of foreign genes, thus contributing to pathogenic adaptation (Aznar et al., 2013). In summary, H-NS has been well-characterized as a buffer to help the bacterial cell tolerate new horizontal gene transfer events. Over time, these acquired genes have undergone further regulatory refinement for optimal expression in the host environment.

De-repression of H-NS by environmental stimuli is one way through which horizontally acquired genes can be activated in the right environments. Changes to DNA curvature induced by osmolarity or temperature shifts can modify the bridging activity of $\mathrm{H}-\mathrm{NS}$ at specific promoters, allowing for transcription to proceed (Hinton et al., 1992). However, directed activation of virulence genes predominantly occurs through regulatory rewiring of $\mathrm{H}-\mathrm{NS}$ binding elements to put these genes under the control of virulence regulators, or to allow for transcription factor binding that displaces H-NS bridges from the DNA. Examples of these methods have been identified for counter-silencing H-NS at horizontally acquired virulence genes in Salmonella, and their significance is discussed below. 


\section{PhoP-PhoQ: Assimilation of Virulence Determinants into a Conserved System}

Given the extent of xenogeneic silencing in Salmonella, the pathogenic lifestyle is highly reliant upon the evolution of regulators to counter-silence $\mathrm{H}-\mathrm{NS}$ and relieve this repression (Stoebel et al., 2008). Many horizontally acquired genes become incorporated into the regulatory framework of two-component sensory systems, which are embedded in genetic networks to rapidly detect and respond to environmental cues (Wallis and Galyov, 2000). The PhoP-PhoQ regulatory system is highly conserved across bacterial species and governs several aspects of the Salmonella virulence program (Miller et al., 1989) with the regulation of $\sim 5 \%$ of genes (Zwir et al., 2005; Harari et al., 2010). Consisting of a sensor kinase in the inner membrane (PhoQ), and response regulator in the cytoplasm (PhoP), this system senses low $\mathrm{Mg}^{2+}$ (García Véscovi et al., 1996), low pH (Bearson et al., 1997), and cationic antimicrobial peptides (Bader et al., 2005) within the stomach and small intestine to mediate rapid adaptation of Salmonella to the host environment. The detection of these environmental cues results in the positive regulation of PhoP-activated ( $p a g$ ) gene expression, and negative regulation of PhoP-repressed ( $p r g$ ) gene expression (Groisman, 2001). Additionally, PhoPQ activity is involved in the upregulation of both the PmrA-PmrB and SsrASsrB two-component systems, which are both important for intracellular survival (Gunn and Miller, 1996; Deiwick et al., 1999).

The majority of genes identified to be regulated by PhoP-PhoQ have been acquired by horizontal gene transfer (Groisman, 2001) and integrated into the PhoP regulon over evolutionary time. This suggests that horizontally acquired genes co-evolve with the Salmonella genome to become assimilated into existing core regulatory architecture, such that the spatiotemporal expression of virulence determinants is tightly controlled. Interestingly, PhoP appears to act differentially to regulate promoters acquired by horizontal gene transfer relative to those predicted to be ancestral (Will et al., 2014). A comparison of the promoter architectures between foreign and ancestral genes suggests that those that were horizontally acquired bind PhoP flexibly with high variability at a number of positions, whereas those that are part of the core genome interact with PhoP in a conserved manner at one binding site (Zwir et al., 2005, 2012). Furthermore, PhoP is capable of activating ancestral promoters directly via RNA polymerase holoenzyme interaction (Will et al., 2014), but horizontally acquired promoters only by countersilencing of H-NS (Will et al., 2015). The importance of PhoPQ in regulating horizontally acquired genes is also evident from the divergence in PhoP targets despite the conservation of this regulatory system across diverse taxa. For example, Yersinia pestis (Grabenstein et al., 2006), Shigella flexneri (Moss et al., 2000), Erwinia carotovora (Flego et al., 2000), Klebsiella pneumoniae (Cheng et al., 2010), and Sodalis glossinidius (Toh et al., 2006) all contain PhoPQ and are severely attenuated for fitness in its absence, but have strikingly different lifestyles and highly distinct PhoP regulons (Groisman, 2001). These findings indicate that PhoPQ is a broadly conserved regulatory system that can flexibly integrate ancestral and acquired genes to accommodate bacterial lifestyles ranging from endosymbiosis to parasitism.

\section{SsrA-SsrB: cis-Regulatory Evolution within the Dichotomous Salmonella Species}

The SsrA-SsrB two-component regulatory system activates the T3SS-2 and is essential for survival and replication within host immune cells (Fass and Groisman, 2009). SsrB can directly bind to genes within SPI-2, and outside of this island, and activate their transcription (Worley et al., 2000; Walthers et al., 2007). This activity is mediated by a flexible 18 base pair palindromic sequence in 7-4-7' architecture upstream of SsrBregulated genes, allowing SsrB to regulate $~ 5 \%$ of the Salmonella genome (Tomljenovic-Berube et al., 2010). Interestingly, in the absence of H-NS, SsrB is less required for SPI-2 gene expression, and relatively recent work has demonstrated that SsrB can directly displace H-NS polymers along DNA (Walthers et al., 2011). Additionally, SsrB mediates a key regulatory crosstalk between SPI-1 and SPI-2. For example, SPI-2-encoded SsrB downregulates SPI-1 genes by repressing HilA and HilD (Pérez-Morales et al., 2017), and reciprocally, SPI-1-encoded HilD upregulates SPI-2 gene expression by directly binding the ssrAB operon (Bustamante et al., 2008). This further demonstrates the cross-talk between pathogenicity islands in order to regulate the different lifestyles of Salmonella during infection.

The classical definition of cis-regulatory evolution rests upon the inevitable accumulation of mutations in noncoding DNA that drift in the nearly neutral range (Stone and Wray, 2001). Those mutations that generate a fitnessincreasing quantitative output to alter gene expression may sweep to fixation, creating novel regulatory nodes that result in the flexible expansion of complex genetic networks (Wray, 2007). Adaptation within cis-regulatory elements is proposed to contribute to genetic tunability in response to environmental cues, a critical component of host colonization. However, up until recently, empirical evidence for this in the context of bacterial pathogenesis was largely lacking. Recent work has shown that mutations in non-coding DNA are targets for polymorphism-fixing selection to assimilate genes into the SsrB regulon, and that divergence in the regulatory patterns between $S$. enterica and S. bongori (which lacks SsrB) confers pathoadaptive fitness differences. For example, we demonstrated that following acquisition of a new regulatory system, the promoters that regulate ancestral genes can evolve responsiveness to the new transcription factor to fine-tune fitness in the host (Osborne et al., 2009). This involves rewiring the cis-regulatory element controlling the ancestral gene that generates phenotypic diversity among the bacterial population that is selective in the host setting. Regulatory evolution explains much of the organismal diversity among closely related animals in the context of developmental evolution (i.e., "evo-devo") however these findings suggested that regulatory evolution might be a more broadly applicable evolutionary principle. Work by other groups has since verified and extended these findings, showing that regulatory evolution drives diverse bacterial traits including 
immune evasion (Tuinema et al., 2014), antibiotic resistance (Horii et al., 1999), and virulence (Li et al., 2009).

\section{THE IMPORTANCE OF GENE LOSS TO PATHOADAPTATION IN SALMONELLA}

While the contribution of horizontally acquired genes in the pathoadaptation of Salmonella has been well-studied, the role of gene loss has received somewhat less attention. Bacterial adaptation to the host environment is understood to involve considerable genomic rearrangement and several studies have addressed the continuously fluctuating size of bacterial genomes, attributed largely to horizontal gene transfer, gene loss, and duplication (Bliven and Maurelli, 2012). We have described how cis-regulatory evolution mediates the assimilation of acquired virulence determinants into existing regulatory circuitry; gene loss is another process whereby certain genes may be inactivated to permit a pathogen's newly acquired virulence factors (Maurelli et al., 1998). Several studies have suggested that an intracellular lifestyle and host range specificity facilitate genomic degradation across the Salmonella serovars, resembling that which occurs in obligate intracellular endosymbionts that are entirely dependent on their eukaryotic hosts (Parkhill et al., 2001; Thomson et al., 2008; Nuccio and Bäumler, 2014). Within bacteria, gene loss proceeds by either genomic rearrangement or pseudogenization. We might predict that this occurs more readily within the host environment encountered by Salmonella during an infection, due to drastic population bottlenecks. These repeated reductions in population size force the random resampling of allelic variation, such that loss-of-function mutations accumulate more rapidly than expected (Nilsson et al., 2005; Albalat and Cañestro, 2016).

How is gene loss identified in bacterial genomes? Phylogenetic reconstruction is often sufficient to reveal the absence of genes when related species are compared to their last common ancestor. The presence of segregating variants with loss-of-function mutations in a population may also signify gene loss. However, these approaches are limited by the accuracy of phylogenetic inference, and additionally complicated in the case of prokaryotic species with genes lacking phylogenetic signal (Albalat and Cañestro, 2016). Exploring phylogenetic relationships with more evolutionary distance is a potential strategy to aid in the detection of reductive evolution. For example, the distantly related tsetse fly endosymbiont $S$. glossinidius possess a genomic region with strong sequence similarity to SPI-2 in Salmonella, and may be used to derive phylogenetic signal necessary for molecular evolutionary analyses. However, an alternative method to characterize patterns of gene loss is with experimental evolution studies that mimic the intracellular environment encountered by bacteria, to measure deletion rates and identify potential fitness advantages. Experiments of this nature are the largest contributors to our current understanding of the evolution of the salmonellae via gene loss.

Investigations of long-term experimental evolution have revealed high rates of deletion in bacteria conferring fitness advantages (Barrick et al., 2009; Khan et al., 2011). In experimentally evolved Salmonella populations simulating conditions of infection, genetic drift has been shown to drive
RecA-independent gene deletions ranging from 1 to $202 \mathrm{~kb}$ over a strikingly brief period of time (Nilsson et al., 2005). Others have shown that selection is also capable of driving random deletions to fixation in the Salmonella chromosome that increase fitness as measured by growth rate (Koskiniemi et al., 2012). Furthermore, analyses of the more pathogenic Typhi and Paratyphi serovars have revealed low rates of purifying selection and recombination, but rather considerable loss-of-function gene mutations (Holt et al., 2008). A higher incidence of pseudogene formation and gene loss have been demonstrated in Paratyphi and Typhi relative to Typhimurium, perhaps due to their increased virulence and/or smaller host range (McClelland et al., 2004).

Why do gene loss mutations confer fitness increases in Salmonella? One hypothesis is that these readily occur in genes participating in pathways that become non-essential in new environmental conditions. As novel host adaptation occurs, neutral mutations may accumulate in these superfluous genes, mediating pseudogenization. Another proposed explanation for gene loss is that loss-of-function mutations occur exclusively in "antivirulence" genes: genes that are antagonistically pleiotropic and incompatible with horizontally acquired virulence determinants (Bliven and Maurelli, 2012). An example of this in Salmonella is the loss of the lacI repressor, which negatively regulates the lactose fermentation system in E. coli, a process that is not required by Salmonella residing in the gastrointestinal environment with access to dietary glucose (Eswarappa et al., 2009). The loss of this gene has been demonstrated to confer fitness advantages, as bacteria expressing it are capable of invasion but attenuated for survival within murine macrophages. It has been proposed that LacI was lost within $S$. Typhimurium to facilitate the acquisition of SPI-2, as it was found to repress virulence genes within this island and remains present in S. bongori, which lacks SPI-2 (Eswarappa et al., 2009). These findings suggest that LacI is an antivirulence gene that underwent selection for loss to promote an intracellular lifestyle.

\section{SALMONELLA INFECTION BIOLOGY IN THE POST-GENOMICS ERA}

The "post-genomics" era has seen several advancements in next-generation sequencing to facilitate the rapid, costeffective generation of completed microbial genome sequences. An increased emphasis on comparative genomics and transcriptomics of cells during infection has improved our ability to detect horizontal gene transfer events and identify the origins of virulence evolution (Thompson et al., 2006; Medini et al., 2008). The advent of RNA-sequencing (RNA-Seq) in particular has heralded an era of Salmonella research that has uncovered several novel aspects of innate immune evasion, as is evidenced by several recent transcriptomics experiments.

To identify the gene expression changes induced by host immune pressures, RNA-Seq was performed on Salmonella grown in 22 in vitro conditions approximating those presented by the immune system over the course of infection. This study identified upregulated expression in $86 \%$ of all $S$. Typhimurium genes (Kroger et al., 2013); subsequent work identified 31 genes that are differentially regulated between growth in vitro and 
within a murine macrophage model of infection (Srikumar et al., 2015). The regulatory nature of Salmonella-host interactions was characterized using RNA-Seq to explore the targets of 18 key transcriptional regulators within $S$. Typhimurium, which identified 1,257 genes with altered expression profiles (Colgan et al., 2016). Interestingly, single-cell RNA-Seq within macrophages identified that Salmonella undergoing active replication shifts macrophage metabolism from an M1 to an M2 polarization state, perhaps capitalizing upon the antiinflammatory environment in M2 macrophages (Saliba et al., 2016). These Salmonella-based RNA-Seq experiments have all explored gene expression profiles during intracellular survival and upon exposure to components of host immunity, as well as helped to identify the genome-wide targets of core transcription factors and how they link to horizontally acquired genes.

\section{SUMMARY}

The interaction of Salmonella with the host during an infection requires sensing the host environment, activating genes in response to host antimicrobial defenses, and modifying the host to make it more amenable for colonization. There are a number of core genes that contribute to pathogenesis, such as motility genes required for chemotaxis within the gut lumen, fimbrial adhesins involved in mediating host cell contact, and metabolic genes that allow for nutrient acquisition in the competitive anaerobic gut environment. However, the biology of Salmonella in the context of infection is strongly driven by the acquisition of genes through horizontal gene transfer. The identification of SPI-1, shared by all Salmonella species and subspecies, as critical for bacterial mediated endocytosis into epithelial cells initiated decades of research into the role of horizontally acquired genes in Salmonella infections. A combination of tissue culture infections, genetic manipulation of Salmonella, and in vivo infection models have been the mainstay of research approaches to broaden our understanding of how SPIs contribute to Salmonella infection biology. This review highlighted the central contributions of the most recently identified pathogenicity islands in $S$. Typhimurium, and tied these findings into the overarching cellular biology of a $S$. Typhimurium infection. Our summaries of these virulence determinants are not comprehensive, as their precise molecular mechanisms have yet to be fully characterized. Although a number of the SPIs and phage associated genes have been identified as playing a role in virulence or survival within host cells, much remains to be understood in how these interact with other Salmonella genes and with host processes.

We have additionally discussed the complex interplay between horizontal gene transfer and cis-regulatory evolution, and

\section{REFERENCES}

Albalat, R., and Cañestro, C. (2016). Evolution by gene loss. Nat. Rev. Genet. 17, 379-391. doi: 10.1038/nrg.2016.39

Ali, S. S., Soo, J., Rao, C., Leung, A. S., Ngai, D. H. M., Ensminger, A. W., et al. (2014). Silencing by H-NS potentiated the evolution of Salmonella. PLoS Pathog. 10:e1004500. doi: 10.1371/journal.ppat.1004500 described the role of these two biological processes in the promotion of patho-adaptive change. Over evolutionary time, the virulence program of Salmonella has been shaped by the acquisition of pathogenicity islands and phage-associated genes, furthering its divergence from to its closest relative, E. coli, and allowing for novel mechanisms of host invasion and resistance. Concurrently, considerable cis-regulatory change has occurred in the Salmonella genome to integrate horizontally acquired genes and ancestral core genes into new regulatory circuitry, to control their expression such that fitness is optimized. Evolutionary biologists have long appreciated the importance of cis-regulatory evolution in the generation of genetic variation to ultimately drive adaptive change; we have elaborated this to emphasize the impact of this process in increasing bacterial pathogenicity. The assimilation of newly acquired genes into the regulons of $\mathrm{H}-\mathrm{NS}$, PhoP-PhoQ, and SsrA-SsrB, has allowed for the expansion of flexible genetic networks that mediate bacterial pathogenesis and confer pathoadaptive fitness differences. We have also described the genomic degradation and gene loss that occurs alongside the horizontal acquisition of novel genes, due to a combination of relaxed selection and antagonistic pleiotropy. These findings highlight the dynamic genome that underpins the evolution of bacterial pathogenesis. In the age of antibiotic resistance when even the very process of evolution itself is a potential new target (Smith and Romesberg, 2007; Zaneveld et al., 2008; Rasko and Sperandio, 2010), understanding these processes in depth and with quantitative measures will become increasingly important.

\section{AUTHOR CONTRIBUTIONS}

All authors listed have made a substantial, direct, and intellectual contribution to the work, and approved it for publication.

\section{FUNDING}

BI was supported by the Ontario Graduate Scholarship. CT is supported by a Postgraduate Scholarship from the Natural Sciences and Engineering Research Council of Canada. Work in the Coombes lab is supported by the Natural Sciences and Engineering Research Council of Canada, the Canadian Institutes of Health Research, and the Canada Foundation for Innovation. BC is the Canada Research Chair in Infectious Disease Pathogenesis.

\section{ACKNOWLEDGMENTS}

We are grateful to the many fruitful conversations with colleagues over the years that have advanced the fields of regulatory evolution and bacterial pathogenesis.

Ali, S. S., Xia, B., Liu, J., and Navarre, W. W. (2012). Silencing of foreign DNA in bacteria. Curr. Opin. Microbiol. 15, 175-181. doi: 10.1016/j.mib.2011.12.014

Arpaia, N., Godec, J., Lau, L., Sivick, K. E., McLaughlin, L. M., Jones, M. B., et al. (2011). TLR signaling is required for Salmonella typhimurium virulence. Cell 144, 675-688. doi: 10.1016/j.cell.2011.01.031

Aussel, L., Zhao, W., Hébrard, M., Guilhon, A. A., Viala, J. P. M., Henri, S., et al. (2011). Salmonella detoxifying enzymes are sufficient 
to cope with the host oxidative burst. Mol. Microbiol. 80, 628-640. doi: 10.1111/j.1365-2958.2011.07611.x

Aznar, S., Paytubi, S., and Juárez, A. (2013). The Hha protein facilitates incorporation of horizontally acquired DNA in enteric bacteria. Microbiology 159, 545-554. doi: 10.1099/mic.0.062448-0

Bader, M. W., Sanowar, S., Daley, M. E., Scheider, A. R., Cho, U., Xu, W., et al. (2005). Recognition of antimicrobial peptides by a bacterial sensor kinase. Cell 122, 461-472. doi: 10.1016/j.cell.2005.05.030

Barksdale, L., and Arden, S. B. (1974). Persisting bacteriophage infections, lysogeny, and phage conversions. Annu. Rev. Microbiol. 28, 265-300. doi: 10.1146/annurev.mi.28.100174.001405

Barrick, J. E., Yu, D. S., Yoon, S. H., Jeong, H., Oh, T. K., Schneider, D., et al. (2009). Genome evolution and adaptation in a long-term experiment with Escherichia coli. Nature 461, 1243-1247. doi: 10.1038/nature08480

Barthel, M., Hapfelmeier, S., Quintanilla-Martínez, L., Kremer, M., Rohde, M., Hogardt, M., et al. (2003). Pretreatment of mice with streptomycin provides a Salmonella enterica serovar Typhimurium colitis model that allows analysis of both pathogen and host. Infect. Immun. 71, 2839-2858. doi: 10.1128/IAI.71.5.2839-2858.2003

Bäumler, A. J. (1997). The record of horizontal gene transfer in Salmonella. Trends Microbiol. 5, 318-122. doi: 10.1016/S0966-842X(97)01082-2

Bearson, S., Bearson, B., and Foster, J. W. (1997). Acid stress responses in enterobacteria. FEMS Microbiol. Rev. 147, 173-180. doi: 10.1111/j.1574-6968.1997.tb10238.x

Bevins, C. L., and Salzman, N. H. (2011). Paneth cells, antimicrobial peptides and maintenance of intestinal homeostasis. Nat. Rev. Microbiol. 9, 356-368. doi: $10.1038 /$ nrmicro2546

Blanc-Potard, A. B., and Groisman, E. A. (1997). The Salmonella selC locus contains a pathogenicity island mediating intramacrophage survival. EMBO J. 16, 5376-5385. doi: 10.1093/emboj/16.17.5376

Bliven, K. A., and Maurelli, A. T. (2012). Antivirulence genes: Insights into pathogen evolution through gene loss. Infect. Immun. 80, 4061-4070. doi: 10.1128/IAI.00740-12

Blondel, C. J., Jiménez, J. C., Contreras, I., and Santiviago, C. A. (2009). Comparative genomic analysis uncovers 3 novel loci encoding type six secretion systems differentially distributed in Salmonella serotypes. BMC Genomics 10:354. doi: 10.1186/1471-2164-10-354

Bogomolnaya, L. M., Santiviago, C. A., Yang, H. J., Bäumler, A. J., and AndrewsPolymenis, H. L. (2008). "Form variation" of the O12 antigen is critical for persistence of Salmonella typhimurium in the murine intestine. Mol. Microbiol. 70, 1105-1119. doi: 10.1111/j.1365-2958.2008.06461.x

Brüssow, H., Canchaya, C., and Hardt, W.-D. (2004). Phages and the evolution of bacterial pathogens: from genomic rearrangements to lysogenic conversion. Microbiol. Mol. Biol. Rev. 68, 560-602. doi: 10.1128/MMBR.68.3.560-602.2004

Buckling, A., and Rainey, P. B. (2002). Antagonistic coevolution between a bacterium and a bacteriophage. Proc. R. Soc. Lond. B 269, 931-936. doi: $10.1098 /$ rspb.2001.1945

Bustamante, V. H., Martínez, L. C., Santana, F. J., Knodler, L. A., SteeleMortimer, O., and Puente, J. L. (2008). HilD-mediated transcriptional crosstalk between SPI-1 and SPI-2. Proc. Natl. Acad. Sci. U.S.A. 105, 14591-14596. doi: 10.1073/pnas.0801205105

Cheetham, B. F., and Katz, M. E. (1995). A role for bacteriophages in the evolution and transfer of bacterial virulence determinants. Mol. Microbiol. 18, 201-208. doi: 10.1111/j.1365-2958.1995.mmi_18020201.X

Chen, H., Yang, D., Han, F., Tan, J., Zhang, L., Xiao, J., et al. (2017). The bacterial T6SS effector EvpP prevents NLRP3 inflammasome activation by inhibiting the Ca2+ - dependent MAPK-Jnk pathway. Cell Host Microbe 21, 47-58. doi: 10.1016/j.chom.2016.12.004

Cheng, H. Y., Chen, Y. F., and Peng, H. L. (2010). Molecular characterization of the PhoPQ-PmrD- PmrAB mediated pathway regulating polymyxin B resistance in Klebsiella pneumoniae CG43. J. Biomed. Sci. 17, 1-16. doi: 10.1186/1423-0127-17-60

Cherayil, B. J., McCormick, B. A., and Bosley, J. (2000). Salmonella enterica serovar Typhimurium-dependent regulation of inducible nitric oxide synthase expression in macrophages by invasins SipB, SipC, and SipD and effector SopE2. Infect. Immun. 68, 5567-5574. doi: 10.1128/IAI.68.10.5567-5574.2000

Cirillo, D. M., Valdivia, R. H., Monack, D. M., and Falkow, S. (1998). Macrophagedependent induction of the Salmonella pathogenicity island 2 type III secretion system and its role in intracellular survival. Mol. Microbiol. 30, 175-188. doi: 10.1046/j.1365-2958.1998.01048.x

Clark, M. A., Jepson, M. A., Simmons, N. L., and Hirst, B. H. (1994). Preferential interaction of Salmonella typhimurium with mouse Peyer's patch M cells. Res. Microbiol. 145, 543-552. doi: 10.1016/0923-2508(94)90031-0

Colgan, A. M., Kröger, C., Diard, M., Hardt, W. D., Puente, J. L., Sivasankaran, S. K., et al. (2016). The impact of 18 ancestral and horizontallyacquired regulatory proteins upon the transcriptome and sRNA landscape of Salmonella enterica serovar Typhimurium. PLoS Genet. 12:e1006258. doi: 10.1371/journal.pgen.1006258

Coombes, B. K., Wickham, M. E., Brown, N. F., Lemire, S., Bossi, L., Hsiao, W. W. L., et al. (2005a). Genetic and molecular analysis of GogB, a phage-encoded type III-secreted substrate in Salmonella enterica serovar Typhimurium with autonomous expression from its associated phage. J. Mol. Biol. 348, 817-830. doi: 10.1016/j.jmb.2005.03.024

Coombes, B. K., Wickham, M. E., Lowden, M. J., Brown, N. F., and Finlay, B. B. (2005b). Negative regulation of Salmonella pathogenicity island 2 is required for contextual control of virulence during typhoid. Proc. Natl. Acad. Sci. U.S.A. 102, 17460-17465. doi: 10.1073/pnas.0505401102

Cuellar-Mata, P., Jabado, N., Liu, J., Furuya, W., Finlay, B. B., Gros, P., et al. (2002). Nrampl modifies the fusion of Salmonella typhimurium-containing vacuoles with cellular endomembranes in macrophages. J. Biol. Chem. 277, 2258-2265. doi: 10.1074/jbc.M105508200

Deiwick, J., Nikolaus, T., Erdogan, S., and Hensel, M. (1999). Environmental regulation of Salmonella pathogenicity island 2 gene expression. Mol. Microbiol. 31, 1759-1773. doi: 10.1046/j.1365-2958.1999.01312.x

Dorman, C. J. (2007). H-NS, the genome sentinel. Nat. Rev. Microbiol. 5, 157-161. doi: $10.1038 /$ nrmicro1598

Dorsey, C. W., Laarakker, M. C., Humphries, A. D., Weening, E. H., and Bäumler, A. J. (2005). Salmonella enterica serotype Typhimurium MisL is an intestinal colonization factor that binds fibronectin. Mol. Microbiol. 57, 196-211. doi: 10.1111/j.1365-2958.2005.04666.x

Ehrbar, K., and Hardt, W.-D. (2005). Bacteriophage-encoded type III effectors in Salmonella enterica subspecies 1 serovar Typhimurium. Infect. Genet. Evol. 5, 1-9. doi: 10.1016/S1567-1348(04)00071-1

Erhardt, M., and Dersch, P. (2015). Regulatory principles governing Salmonella and Yersinia virulence. Front. Microbiol. 6:949. doi: 10.3389/fmicb.2015.00949

Eshraghi, A., Kim, J., Walls, A. C., Ledvina, H. E., Miller, C. N., and Ramsey, K. M. (2016). Secreted effectors encoded within and outside of the Francisella Pathogenicity Island promote intramacrophage growth. Cell Host Microbe 20, 573-583. doi: 10.1016/j.chom.2016.10.008

Eswarappa, S. M., Karnam, G., Nagarajan, A. G., Chakraborty, S., and Chakravortty, D. (2009). lac repressor is an antivirulence factor of Salmonella enterica : its role in the evolution of virulence in Salmonella. PLoS ONE 4:e5789. doi: 10.1371/journal.pone.0005789

Fass, E., and Groisman, E. A. (2009). Control of Salmonella pathogenicity island-2 gene expression. Curr. Opin. Microbiol. 12, 199-204. doi: 10.1016/j.mib.2009.01.004

Figueira, R., and Holden, D. W. (2012). Functions of the Salmonella pathogenicity island 2 (SPI-2) type III secretion system effectors. Microbiology 158, 1147-1161. doi: 10.1099/mic.0.058115-0

Figueroa-Bossi, N., and Bossi, L. (1999). Inducible prophages contribute to Salmonella virulence in mice. Mol. Microbiol. 33, 167-176. doi: 10.1046/j.1365-2958.1999.01461.x

Figueroa-Bossi, N., Uzzau, S., Maloriol, D., and Bossi, L. (2001). Variable assortment of prophages provides a transferable repertoire of pathogenic determinants in Salmonella. Mol. Microbiol. 39, 260-271. doi: 10.1046/j.1365-2958.2001.02234.x

Finlay, B. B., and Brumell, J. H. (2000). Salmonella interactions with host cells: in vitro to in vivo. Philos. Trans. R. Soc. Lond. B Biol. Sci. 355, 623-631. doi: $10.1098 /$ rstb.2000.0603

Flego, D., Marits, R., Eriksson, A. R. B., Kõiv, V., Karlsson, M. B., Palva, E. T., et al. (2000). A two-component regulatory system, PehR-PehS, controls endopolygalacturonase production and virulence in the plant pathogen Erwinia carotovora subsp. carotovora. Mol. Plant Microbe Interact. 13, 447-455. doi: 10.1094/MPMI.2000.13.4.447

Fookes, M., Schroeder, G. N., Langridge, G. C., Blondel, C. J., Mammina, C., Connor, T. R., et al. (2011). Salmonella bongori provides insights 
into the evolution of the salmonellae. PLoS Pathog. 7:e1002191. doi: 10.1371/journal.ppat.1002191

Gal-Mor, O., and Finlay, B. B. (2006). Pathogenicity islands: a molecular toolbox for bacterial virulence. Cell Microbiol. 8, 1707-1719. doi: $10.1111 / j .1462-5822.2006 .00794 . x$

García Véscovi, E., Soncini, F. C., and Groisman, E. A. (1996). Mg2+ as an extracellular signal: environmental regulation of Salmonella virulence. Cell 84, 165-174. doi: 10.1016/S0092-8674(00)81003-X

García-Del Portillo, F. (2001). Salmonella intracellular proliferation: Where, when and how? Microbes Infect. 3, 1305-1311. doi: 10.1016/S1286-4579(01) 01491-5

Geddes, K., Cruz, I. I. I., F., and Heffron, F. (2007). Analysis of cells targeted by Salmonella type III secretion in vivo. PLoS Pathog. 3:e196. doi: 10.1371/journal.ppat.0030196

Gerlach, R. G., Jäckel, D., Geymeier, N., and Hensel, M. (2007). Salmonella pathogenicity island 4-mediated adhesion is coregulated with invasion genes in Salmonella enterica. Infect. Immun. 75, 4697-4709. doi: 10.1128/IAI.00228-07

Gewirtz, A. T., Navas, T. A., Lyons, S., Godowski, P. J., and Madara, J. L. (2001). Bacterial flagellin activates basolaterally expressed TLR5 to induce epithelial proinflammatory gene expression. J. Immunol. 167, 1882-1885. doi: 10.4049/jimmunol.167.4.1882

Giammanco, G. M., Pignato, S., Mammina, C., Grimont, F., Grimont, P. A. D., Nastasi, A., et al. (2002). Persistent endemicity of Salmonella bongori 48:z35:- in southern Italy: molecular characterization of human, animal, and environmental isolates. J. Clin. Microbiol. 40, 3502-3505. doi: 10.1128/JCM.40.9.3502-3505.2002

Grabenstein, J. P., Fukuto, H. S., Palmer, L. E., and Bliska, J. B. (2006). Characterization of phagosome trafficking and identification of PhoP-regulated genes important for survival of Yersinia pestis in macrophages. Infect. Immun. 74, 3727-3741. doi: 10.1128/IAI.00255-06

Groisman, E. A. (2001). The pleiotropic two-component regulatory system PhoPPhoQ. J. Bacteriol. 183, 1835-1842. doi: 10.1128/JB.183.6.1835-1842.2001

Groisman, E. A., and Ochman, H. (1996). Pathogenicity islands: bacterial evolution in quantum leaps. Cell 87, 791-794. doi: 10.1016/S0092-8674(00)81985-6

Groisman, E. A., and Ochman, H. (1997). How Salmonella became a pathogen. Trends Microbiol. 5, 343-349. doi: 10.1016/S0966-842X(97)01099-8

Gunn, J. S., Alpuche-Aranda, C. M., Loomis, W. P., Belden, W. J., and Miller, S. I. (1995). Characterization of the Salmonella typhimurium pagC/pagD chromosomal region. J. Bacteriol. 177, 5040-5047. doi: 10.1128/jb.177.17.5040-5047.1995

Gunn, J. S., and Miller, S. I. (1996). PhoP-PhoQ activates transcription of pmrAB, encoding a two-component regulatory system involved in Salmonella typhimurium antimicrobial peptide resistance. J. Bacteriol. 178, 6857-6864. doi: 10.1128/jb.178.23.6857-6864.1996

Haneda, T., Ishii, Y., Danbara, H., and Okada, N. (2009). Genome-wide identification of novel genomic islands that contribute to Salmonella virulence in mouse systemic infection. FEMS Microbiol. Lett. 297, 241-249. doi: $10.1111 / j .1574-6968.2009 .01686 . x$

Hansen-Wester, I., and Hensel, M. (2001). Salmonella pathogenicity islands encoding type III secretion systems. Microbes Infect. 3, 549-559. doi: 10.1016/S1286-4579(01)01411-3

Hansen-Wester, I., and Hensel, M. (2002). Genome-based identification of chromosomal regions specific for Salmonella spp. Infect. Immun. 70, 2351-2360. doi: 10.1128/IAI.70.5.2351-2360.2002

Haraga, A., and Miller, S. I. (2006). A Salmonella type III secretion effector interacts with the mammalian serine / threonine protein kinase PKN1. Cell Microbiol. 8, 837-846. doi: 10.1111/j.1462-5822.2005.00670.x

Haraga, A., Ohlson, M. B., and Miller, S. I. (2008). Salmonellae interplay with host cells. Nat. Rev. Microbiol. 6, 53-66. doi: 10.1038/nrmicro1788

Harari, O., Park, S. Y., Huang, H., Groisman, E. A., and Zwir, I. (2010). Defining the plasticity of transcription factor binding sites by deconstructing DNA consensus sequences : the PhoP-binding sites among Gamma / Enterobacteria. PLoS Comput. Biol. 6:e1000862. doi: 10.1371/journal.pcbi.1000862

Henard, C. A., and Vázquez-Torres, A. (2011). Nitric oxide and Salmonella pathogenesis. Front. Microbiol. 2:84. doi: 10.3389/fmicb.2011.00084

Hensel, M. (2000). Salmonella Pathogenicity Island 2. Mol. Microbiol. 36, 1015-1023. doi: 10.1046/j.1365-2958.2000.01935.x
Hensel, M., Hinsley, A. P., Nikolaus, T., Sawers, G., and Berks, B. C. (1999). The genetic basis of tetrathionate respiration in Salmonella typhimurium. Mol. Microbiol. 32, 275-287. doi: 10.1046/j.1365-2958.1999.01345.x

Hensel, M., Shea, J. E., Waterman, S. R., Mundy, R., Nikolaus, T., Banks, G., et al. (1998). Genes encoding putative effector proteins of the type III secretion system of Salmonella pathogenicity island 2 are required for bacterial virulence and proliferation in macrophages. Mol. Microbiol. 30, 163-174. doi: 10.1046/j.1365-2958.1998.01047.x

Higashi, K., Tobe, T., Kanai, A., Uyar, E., and Ishikawa, S. (2016). HNS facilitates sequence diversification of horizontally transferred DNAs during their integration in host chromosomes. PLoS Genet. 12:e1005796. doi: 10.1371/journal.pgen.1005796

Hinton, J. C. D., Santos, D. S., Seirafi, A., Hulton, C. S. J., Pavitt, G. D., and Higgins, C. F. (1992). Expression and mutational analysis of the nucleoid-associated protein H-NS of Salmonella typhimurium. Mol. Microbiol. 6, 2327-2337. doi: 10.1111/j.1365-2958.1992.tb01408.x

Holt, K. E., Parkhill, J., Mazzoni, C. J., Roumagnac, P., Goodhead, I., Rance, R., et al. (2008). High-throughput sequencing provides insights into genome variation and evolution in Salmonella Typhi. Nat. Genet. 40, 987-993. doi: 10.1038/ng.195

Horii, T., Kimura, T., Sato, K., Shibayama, K., and Ohta, M. (1999). Emergence of fosfomycin-resistant isolates of shiga-like toxin-producing Escherichia coli O26. Antimicrob. Agents Chemother. 43, 789-793.

Jiang, L., Feng, L., Yang, B., Zhang, W., Wang, P., Jiang, X., et al. (2017). Signal transduction pathway mediated by the novel regulator LoiA for low oxygen tension induced Salmonella Typhimurium invasion. PLoS Pathog. 13:e1006429. doi: 10.1371/journal.ppat.1006429

Johansson, C., Ingman, M., and Jo Wick, M. (2006). Elevated neutrophil, macrophage and dendritic cell numbers characterize immune cell populations in mice chronically infected with Salmonella. Microb. Pathog. 41, 49-58. doi: 10.1016/j.micpath.2006.03.004

Khan, A. I., Dinh, D. M., Schneider, D., Lenski, R. E., and Cooper, T. F. (2011). Negative epistasis between beneficial mutations in an evolving bacterial population. Science 332, 1193-1196. doi: 10.1126/science.1203801

Knodler, L. A. (2015). Salmonella enterica: living a double life in epithelial cells. Curr. Opin. Microbiol. 23, 23-31. doi: 10.1016/j.mib.2014.10.010

Knodler, L. A., Celli, J., Hardt, W. D., Vallance, B. A., Yip, C., and Finlay, B. B. (2002). Salmonella effectors within a single pathogenicity island are differentially expressed and translocated by separate type III secretion systems. Mol. Microbiol. 43, 1089-1103. doi: 10.1046/j.1365-2958.2002.02820.x

Knodler, L. A., Nair, V., and Steele-Mortimer, O. (2014). Quantitative assessment of cytosolic Salmonella in epithelial cells. PLoS ONE 9:e84681. doi: 10.1371/journal.pone.0084681

Knodler, L. A., Vallance, B. A., Celli, J., Winfree, S., Hansen, B., Montero, M., et al. (2010). Dissemination of invasive Salmonella via bacterial-induced extrusion of mucosal epithelia. Proc. Natl. Acad. Sci. U.S.A. 107, 17733-17738. doi: 10.1073/pnas.1006098107

Kolachala, V. L., Bajaj, R., Wang, L., Yan, Y., Ritzenthaler, J. D., Gewirtz, A. T., et al. (2007). Epithelial-derived fibronectin expression, signaling, and function in intestinal inflammation. J. Biol. Chem. 282, 32965-32973. doi: 10.1074/jbc.M704388200

Koskiniemi, S., Sun, S., Berg, O. G., and Andersson, D. I. (2012). Selection-driven gene loss in bacteria. PLoS Genet. 8:e1002787. doi: 10.1371/journal.pgen.1002787

Kroger, C., Colgan, A., Srikumar, S., Handler, K., Sivasankaran, S. K., Hammarlof, D. L., et al. (2013). An infection-relevant transcriptomic compendium for Salmonella enterica serovar Typhimurium. Cell Host Microbe 14, 683-695. doi: 10.1016/j.chom.2013.11.010

Lee, C. A., Silva, M., Siber, A. M., Kelly, A. J., Galyov, E., and McCormick, B. A. (2000). A secreted Salmonella protein induces a proinflammatory response in epithelial cells, which promotes neutrophil migration. Proc. Natl. Acad. Sci. U.S.A. 97, 12283-12288. doi: 10.1073/pnas.97.22.12283

Li, M., Diep, B. A., Villaruz, A. E., Braughton, K. R., Jiang, X., DeLeo, F. R., et al. (2009). Evolution of virulence in epidemic community-associated methicillinresistant Staphlycoccus aureus. Proc. Natl. Acad. Sci. U.S.A. 106, 5883-5888. doi: 10.1073/pnas.0900743106

Lopez, C. A., Winter, S. E., Rivera-Chávez, F., Xavier, M. N., Poon, V., Nuccio, S. P., et al. (2012). Phage-mediated acquisition of a type III secreted effector 
protein boosts growth of Salmonella by nitrate respiration. mBio 3, 1-10. doi: 10.1128/mBio.00143-12

Lorkowski, M., Felipe-López, A., Danzer, C. A., Hansmeier, N., and Hensel, M. (2014). Salmonella enterica invasion of polarized epithelial cells is a highly cooperative effort. Infect. Immun. 82, 2657-2667. doi: 10.1128/IAI.00023-14

Lostroh, C. P., and Lee, C. A. (2001). The Salmonella pathogenicity island-1 type III secretion system. Microbes Infect. 3, 1281-1291. doi: 10.1016/S1286-4579(01)01488-5

Lucchini, S., Rowley, G., Goldberg, M. D., Hurd, D., Harrison, M., and Hinton, J. C. D. (2006). H-NS mediates the silencing of laterally acquired genes in bacteria. PLoS Pathog. 2:e81. doi: 10.1371/journal.ppat.0020081

Maurelli, A. T., Fernández, R. E., Bloch, C. A., Rode, C. K., and Fasano, A. (1998). "Black holes" and bacterial pathogenicity: a large genomic deletion that enhances the virulence of Shigella spp. and enteroinvasive Escherichia coli. Proc. Natl. Acad. Sci. U.S.A. 95, 3943-3948. doi: 10.1073/pnas.95.7.3943

McClelland, M., Sanderson, K. E., Clifton, S. W., Latreille, P., Porwollik, S., Sabo, A., et al. (2004). Comparison of genome degradation in Paratyphi A and Typhi, human-restricted serovars of Salmonella enterica that cause typhoid. Nat. Genet. 36, 1268-1274. doi: 10.1038/ng1470

McClelland, M., Sanderson, K. E., Spieth, J., Clifton, S. W., Latreille, P., Courtney, L., et al. (2001). Complete genome sequence of Salmonella enterica serovar Typhimurium LT2. Nature 413, 852-856. doi: 10.1038/35101614

McGhie, E. J., Brawn, L. C., Hume, P. J., Humphreys, D., and Koronakis, V. (2009). Salmonella takes control: effector-driven manipulation of the host. Curr. Opin. Microbiol. 12, 117-124. doi: 10.1016/j.mib.2008.12.001

McGuckin, M. A., Lindén, S. K., Sutton, P., and Florin, T. H. (2011). Mucin dynamics and enteric pathogens. Nat. Rev. Microbiol. 9, 265-278. doi: $10.1038 /$ nrmicro2538

McQuiston, J. R., Herrera-Leon, S., Wertheim, B. C., Doyle, J., Fields, P. I., Logsdon, J. M. Jr., et al. (2008). Molecular phylogeny of the Salmonellae: relationships among Salmonella species and subspecies determined from four housekeeping genes and evidence of lateral gene transfer events. J. Bacteriol. 190, 7060-7067. doi: 10.1128/JB.01552-07

Medini, D., Serruto, D., Parkhill, J., Relman, D. A., Donati, C., Moxon, R., et al. (2008). Microbiology in the post-genomic era. Nat. Rev. Microbiol. 6, 419-430. doi: $10.1038 /$ nrmicro1901

Miao, E. A., Scherer, C. A., Tsolis, R. M., Kingsley, R. A., Adams, L. G., Bäumler, A. J., et al. (1999). Salmonella typhimurium leucine-rich repeat proteins are targeted to the SPI1 and SPI2 type III secretion systems. Mol. Microbiol. 34, 850-864. doi: 10.1046/j.1365-2958.1999.01651.x

Miller, S. I., Kukral, A. M., and Mekalanos, J. J. (1989). A two-component regulatory system (phoP phoQ) controls Salmonella typhimurium virulence. Proc. Natl. Acad. Sci. U.S.A. 86, 5054-5058. doi: 10.1073/pnas.86.13.5054

Mirold, S., Rabsch, W., Tschäpe, H., and Hardt, W. D. (2001). Transfer of the Salmonella type III effector sopE between unrelated phage families. J. Mol. Biol. 312, 7-16. doi: 10.1006/jmbi.2001.4950

Morgan, E., Bowen, A. J., Carnell, S. C., Wallis, T. S., and Stevens, M. P. (2007). SiiE is secreted by the Salmonella enterica serovar typhimurium pathogenicity island 4-encoded secretion system and contributes to intestinal colonization in cattle. Infect. Immun. 75, 1524-1533. doi: 10.1128/IAI.01438-06

Morgan, E., Campbell, J. D., Rowe, S. C., Bispham, J., Stevens, M. P., Bowen, A. J., et al. (2004). Identification of host-specific colonization factors of Salmonella enterica serovar Typhimurium. Mol. Microbiol. 54, 994-1010. doi: 10.1111/j.1365-2958.2004.04323.x

Moss, J. E., Fisher, P. E., Vick, B., Groisman, E. A., and Zychlinsky, A. (2000). The regulatory protein PhoP controls susceptibility to the host inflammatory response in Shigella flexneri. Cell Microbiol. 2, 443-452. doi: 10.1046/j.1462-5822.2000.00065.x

Mulder, D. T., Cooper, C. A., and Coombes, B. K. (2012). Type VI secretion system-associated gene clusters contribute to pathogenesis of Salmonella enterica serovar Typhimurium. Infect. Immun. 80, 1996-2007. doi: 10.1128/IAI.06205-11

Nastasi, A., Mammina, C., Villafrate, M. R., Massenti, M. F., Scarlata, G., and Diquattro, M. (1988). Multiple typing of strains of Salmonella enterica subsp. Bongori ser. 48:z35:- isolated in southern Italy. Ann. Inst. Pasteur/Microbiol. 139, 605-612. doi: 10.1016/0769-2609(88)90158-5

Navarre, W. W., McClelland, M., Libby, S. J., and Fang, F. C. (2007). Silencing of xenogeneic DNA by H-NS - facilitation of lateral gene transfer in bacteria by a defense system that recognizes foreign DNA. Genes Dev. 21, 1456-1471. doi: 10.1101/gad.1543107

Navarre, W. W., Porwollik, S., Wang, Y., McClelland, M., Rosen, H., Libby, S. J., et al. (2006). Selective silencing of foreign DNA with low GC content by the $\mathrm{H}$ NS protein in Salmonella. Science 313, 236-238. doi: 10.1126/science.1128794

Nieto, P. A., Pardo-roa, C., Salazar-Echegarai, F. J., Tobar, H. E., CoronadoArrázola, I., Riedel, C. A., et al. (2016). New insights about excisable pathogenicity islands in Salmonella and their contribution to virulence. Microbes Infect. 18, 302-309. doi: 10.1016/j.micinf.2016.02.001

Nilsson, A. I., Koskiniemi, S., Eriksson, S., Kugelberg, E., Hinton, J. C. D., and Andersson, D. I. (2005). Bacterial genome size reduction by experimental evolution. Proc. Natl. Acad. Sci. U.S.A. 102, 12112-12116. doi: 10.1073/pnas.0503654102

Nuccio, S. P., and Bäumler, A. J. (2014). Comparative analysis of Salmonella genomes identifies a metabolic network for escalating growth in the inflamed gut. mBio 5:e0929-14. doi: 10.1128/mBio.00929-14

Ochman, H., Lawrence, J. G., and Groisman, E. A. (2000). Lateral gene transfer and the nature of bacterial innovation. Nature 405, 299-304. doi: 10.1038/35012500

Ochman, H., Soncini, F. C., Solomon, F., and Groisman, E. A. (1996). Identification of a pathogenicity island required for Salmonella survival in host cells. Proc. Natl. Acad. Sci. U.S.A. 93, 7800-7804. doi: 10.1073/pnas.93.15.7800

Osborne, S. E., Walthers, D., Tomljenovic, A. M., Mulder, D. T., Silphaduang, U., Duang, N., et al. (2009). Pathogenic adaptation of intracellular bacteria by rewiring a cis-regulatory input function. Proc. Natl. Acad. Sci. U.S.A. 106, 3962-1987. doi: 10.1073/pnas.0811669106

Parkhill, J., Dougan, G., James, K. D., Thomson, N. R., Pickard, D., Wain, J., et al. (2001). Complete genome sequence of a multiple drug resistant Salmonella enterica serovar Typhi CT18. Nature 413, 848-852. doi: 10.1038/35101607

Patel, S., and McCormick, B. A. (2014). Mucosal inflammatory response to Salmonella typhimurium infection. Front. Immunol. 5:311. doi: 10.3389/fimmu.2014.00311

Pérez-Morales, D., Banda, M. M., Chau, N. Y. E., Salgado, H., Martínez-Flores, I., Ibarra, J. A., et al. (2017). The transcriptional regulator SsrB is involved in a molecular switch controlling virulence lifestyles of Salmonella. PLOS Pathog. 13:e1006497. doi: 10.1371/journal.ppat.1006497

Perrett, C. A., and Zhou, D. (2013). Salmonella type III effector SopB modulates host cell exocytosis. Emerg. Microbes Infect. 2:e32. doi: 10.1038/emi. 2013.31

Pilar, A. V. C., Reid-Yu, S. A., Cooper, C. A., Mulder, D. T., and Coombes, B. K. (2012). GogB Is an Anti-Inflammatory Effector that Limits Tissue Damage during Salmonella Infection through Interaction with Human FBXO22 and Skp1. PLoS Pathog. 8:e1002773. doi: 10.1371/journal.ppat.1002773

Que, F., Wu, S., and Huang, R. (2013). Salmonella Pathogenicity Island 1 (SPI-1) at work. Curr. Microbiol. 66, 582-587. doi: 10.1007/s00284-013-0307-8

Raffatellu, M., Wilson, R. P., Chessa, D., Andrews-Polymenis, H., Tran, Q. T., Lawhon, S., et al. (2005). SipA, SopA, SopB, SopD, and SopE2 contribute to Salmonella enterica serotype Typhimurium invasion of epithelial cells. Infect. Immun. 73, 146-154. doi: 10.1128/IAI.73.1.146-154.2005

Rasko, D. A., and Sperandio, V. (2010). Anti-virulence strategies to combat bacteria-mediated disease. Nat. Rev. Drug Discov. 9, 117-128. doi: $10.1038 / \mathrm{nrd} 3013$

Rivera-Chávez, F., Winter, S. E., Lopez, C. A., Xavier, M. N., Winter, M. G., Nuccio, S.-P., et al. (2013). Salmonella uses energy taxis to benefit from intestinal inflammation. PLoS Pathog. 9:e1003267. doi: 10.1371/journal.ppat.1003267

Saliba, A. E., Li, L., Westermann, A. J., Appenzeller, S., Stapels, D. A. C., Schulte, L. N., et al. (2016). Single-cell RNA-seq ties macrophage polarization to growth rate of intracellular Salmonella. Nat. Microbiol. 2:16206. doi: $10.1038 /$ nmicrobiol.2016.206

Salzman, N. H., Chou, M. M., de Jong, H., Liu, L., Porter, E. M., and Paterson, Y. (2003). Enteric Salmonella infection inhibits paneth cell antimicrobial peptide expression. Infect. Immun. 71, 1109-1115. doi: 10.1128/IAI.71.3.1109-1115.2003

Sana, T. G., Baumann, C., Merdes, A., Soscia, C., Rattei, T., Hachani, A., et al. (2015). Internalization of Pseudomonas aeruginosa strain PAO1 into epithelial cells is promoted by interaction of a T6SS effector with the microtubule network. mBio 6, e00712-e00715. doi: 10.1128/mBio.00712-15

Sana, T. G., Flaugnatti, N., Lugo, K. A., Lam, L. H., Jacobson, A., Baylot, V., et al. (2016). Salmonella typhimurium utilizes a T6SS-mediated antibacterial weapon 
to establish in the host gut. Proc. Natl. Acad. Sci. U.S.A. 113, E5044-E5051. doi: 10.1073/pnas.1608858113

Sana, T. G., Lugo, K. A., and Monack, D. M. (2017). T6SS: The bacterial "fight club" in the host gut. PLoS Pathog. 13:e1006325. doi: 10.1371/journal.ppat.1006325

Santos, R. L., Raffatellu, M., Bevins, C. L., Adams, L. G., Tükel, Ç., Tsolis, R. M., et al. (2009). Life in the inflamed intestine, Salmonella style. Trends Microbiol. 17, 498-506. doi: 10.1016/j.tim.2009.08.008

Santos, R. L., Zhang, S., Tsolis, R. M., Kingsley, R. A., Adams, L. G., and Bäumler, A. J. (2001). Animal models of Salmonella infections: enteritis versus typhoid fever. Microbes Infect. 3, 1335-1344. doi: 10.1016/S1286-4579(01)01495-2

Schechter, L. M., Jain, S., Akbar, S., and Lee, C. A. (2003). The small nucleoid-binding proteins $\mathrm{H}-\mathrm{NS}, \mathrm{HU}$, and Fis affect hilA expression in Salmonella enterica serovar Typhimurium. Infect. Immun. 71, 5432-5435. doi: 10.1128/IAI.71.9.5432-5435.2003

Shea, J. E., Hensel, M., Gleeson, C., and Holden, D. W. (1996). Identification of a virulence locus encoding a second type III secretion system in Salmonella typhimurium. Proc. Natl. Acad. Sci. U.S.A. 93, 2593-2597. doi: $10.1073 /$ pnas.93.6.2593

Shi, L., Adkins, J. N., Coleman, J. R., Schepmoes, A. A., Dohnkova, A., Mottaz, H. M., et al. (2006). Proteomic analysis of Salmonella enterica serovar Typhimurium isolated from RAW 264.7 macrophages. J. Biol. Chem. 281, 29131-29140. doi: 10.1074/jbc.M604640200

Silphaduang, U., Mascarenhas, M., Karmali, M., and Coombes, B. K. (2007). Repression of intracellular virulence factors in Salmonella by the Hha and YdgT nucleoid-associated proteins. J. Bacteriol. 189, 3669-3673. doi: 10.1128/JB.00002-07

Singh, K., Milstein, J. N., and Navarre, W. W. (2016). Xenogeneic Silencing and Its Impact on Bacterial Genomes. Annu. Rev. Microbiol. 70, 199-213. doi: 10.1146/annurev-micro-102215-095301

Slauch, J. M., Lee, A. A., Mahan, M. J., and Mekalanos, J. J. (1996). Molecular characterization of the oafA locus responsible for acetylation of Salmonella typhimurium O-Antigen: OafA is a member of a family of integral membrane trans-acylases J. Bacteriol. 178, 5904-5909. doi: 10.1128/jb.178.20.5904-5909.1996

Smith, P. A., and Romesberg, F. E. (2007). Combating bacteria and drug resistance by inhibiting mechanisms of persistence and adaptation. Nat. Chem. Biol. 3, 549-556. doi: 10.1038/nchembio.2007.27

Srikumar, S., Kröger, C., Hébrard, M., Colgan, A., Owen, S. V., Sivasankaran, S. K., et al. (2015). RNA-seq brings new insights to the intra-macrophage transcriptome of Salmonella typhimurium. PLOS Pathog. 11:e1005262. doi: 10.1371/journal.ppat.1005262

Stecher, B., Robbiani, R., Walker, A. W., Westendorf, A. M., Barthel, M., Kremer, M., et al. (2007). Salmonella enterica serovar typhimurium exploits inflammation to compete with the intestinal microbiota. PLoS Biol. 5, 2177-2189. doi: 10.1371/journal.pbio.0050244

Stoebel, D. M., Free, A., and Dorman, C. J. (2008). Anti-silencing: overcoming H-NS-mediated repression of transcription in Gram-negative enteric bacteria. Microbiology 154, 2533-2545. doi: 10.1099/mic.0.2008/020693-0

Stone, J. R., and Wray, G. A. (2001). Rapid evolution of cis- regulatory sequences via local point mutations. Mol. Biol. Evol. 18, 1764-1770. doi: 10.1093/oxfordjournals.molbev.a003964

Thompson, A., Rowley, G., Alston, M., Danino, V., and Hinton, J. C. D. (2006). Salmonella transcriptomics: relating regulons, stimulons and regulatory networks to the process of infection. Curr. Opin. Microbiol. 9, 109-116. doi: 10.1016/j.mib.2005.12.010

Thomson, N. R., Clayton, D. J., Windhorst, D., Vernikos, G., Davidson, S., and Churcher, C. (2008). Comparative genome analysis of Salmonella Enteritidis PT4 and Salmonella Gallinarum 287 / 91 provides insights into evolutionary and host adaptation pathways. Genome Res. 18, 1624-1637. doi: 10.1101 /gr.077404.108

Thöne, F., Schwanhäusser, B., Becker, D., Ballmaier, M., and Bumann, D. (2007). FACS-isolation of Salmonella -infected cells with defined bacterial load from mouse spleen. J. Microbiol. Methods 71, 220-224. doi: 10.1016/j.mimet.2007.08.016

Toh, H., Weiss, B. L., Perkin, S. A. H., Yamashita, A., Oshima, K., Hattori, M., et al. (2006). Massive genome erosion and functional adaptations provide insights into the symbiotic lifestyle of Sodalis glossinidius in the tsetse host. Genome Res. 16, 149-156. doi: 10.1101/gr.4106106
Tomljenovic-Berube, A. M., Henriksbo, B., Porwollik, S., Cooper, C. A., Tuinema, B. R., McClelland, M., et al. (2013). Mapping and regulation of genes within Salmonella pathogenicity island 12 that contribute to in vivo fitness of Salmonella enterica serovar Typhimurium. Infect. Immun. 81, 2394-2404. doi: 10.1128/IAI.00067-13

Tomljenovic-Berube, A. M., Mulder, D. T., Whiteside, M. D., Brinkman, F. S. L., and Coombes, B. K. (2010). Identification of the regulatory logic controlling Salmonella pathoadaptation by the SsrA-SsrB two-component system. PLoS Genet. 6:e1000875. doi: 10.1371/journal.pgen.1000875

Tsolis, R. M., Xavier, M. N., Santos, R. L., and Bäumler, A. J. (2011). How to become a top model: impact of animal experimentation on human Salmonella disease research. Infect. Immun. 79, 1806-1814. doi: 10.1128/IAI.01369-10

Tuinema, B. R., Reid-Yu, S. A., and Coombes, B. K. (2014). Salmonella evades D-amino acid oxidase to promote infection in neutrophils. mBio 5, e01886e01814. doi: 10.1128/mBio.01886-14

Tükel, C.., Raffatellu, M., Chessa, D., Wilson, R. P., Akçelik, M., and Bäumler, A. J. (2006). Neutrophil influx during non-typhoidal salmonellosis: who is in the driver's seat? FEMS Immunol. Med. Microbiol. 46, 320-329. doi: 10.1111/j.1574-695X.2006.00051.x

Uzzau, S., Brown, D. J., Wallis, T., Rubino, S., Leori, G., Bernard, S., et al. (2000). Host adapted serotypes of Salmonella enterica. Epidemiol. Infect. 125, 229-255. doi: $10.1017 /$ S0950268899004379

Vazquez-Torres, A., Jones-Carson, J., Mastroeni, P., Ischiropoulos, H., and Fang, F. C. (2000). Antimicrobial actions of the NADPH phagocyte oxidase and inducible nitric oxide synthase in experimental salmonellosis. J. Exp. Med. 192, 227-236. doi: 10.1084/jem.192.2.227

Vimal, D. B., Khullar, M., Gupta, S., and Ganguly, N. K. (2000). Intestinal mucins : the binding sites for Salmonella typhimurium. Mol. Cell. Biochem. 204, 107-117. doi: 10.1023/A:1007015312036

Vivero, A., Baños, R. C., Mariscotti, J. F., Oliveros, J. C., García-Del Portillo, F., Juárez, A., et al. (2008). Modulation of horizontally acquired genes by the HhaYdgT proteins in Salmonella enterica serovar typhimurium. J. Bacteriol. 190, 1152-1156. doi: 10.1128/JB.01206-07

Waldor, M. K. (1998). Bacteriophage biology and bacterial virulence. Trends Microbiol. 6, 295-297. doi: 10.1016/S0966-842X(98)01320-1

Wallis, T. S., and Galyov, E. E. (2000). Molecular basis of Salmonellainduced enteritis. Mol. Microbiol. 36, 997-1005. doi: 10.1046/j.1365-2958.2000. 01892.x

Walthers, D., Carroll, R. K., Navarre, W. W., Libby, S. J., Fang, F. C., and Kenney, L. J. (2007). The response regulator SsrB activates expression of diverse Salmonella pathogenicity island 2 promoters and counters silencing by the nucleoid-associated protein H-NS. Mol. Microbiol. 65, 477-493. doi: $10.1111 / j .1365-2958.2007 .05800 . x$

Walthers, D., Li, Y., Liu, Y., Anand, G., Yan, J., and Kenney, L. J. (2011). Salmonella enterica response regulator SsrB relieves H-NS silencing by displacing H-NS bound in polymerization mode and directly activates transcription. J. Biol. Chem. 286, 1895-1902. doi: 10.1074/jbc.M110.164962

Waterman, S. R., and Holden, D. W. (2003). Functions and effectors of the Salmonella pathogenicity island 2 type III secretion system. Cell. Microbiol. 5, 501-511. doi: 10.1046/j.1462-5822.2003.00294.x

Watson, K. G., and Holden, D. W. (2010). Dynamics of growth and dissemination of Salmonella in vivo. Cell. Microbiol. 12, 1389-1397. doi: 10.1111/j.1462-5822.2010.01511.x

Will, W. R., Bale, D. H., Reid, P. J., Libby, S. J., and Fang, F. C. (2014). Evolutionary expansion of a regulatory network by counter-silencing. Nat. Commun. 5:6270. doi: $10.1038 /$ ncomms 6270

Will, W. R., Navarre, W. W., and Fang, F. C. (2015). Integrated circuits: How transcriptional silencing and counter-silencing facilitate bacterial evolution. Curr. Opin. Microbiol. 23, 8-13. doi: 10.1016/j.mib.2014.10.005

Winter, S. E., Keestra, A. M., Tsolis, R. M., and Bäumler, A. J. (2010a). The blessings and curses of intestinal inflammation. Cell Host Microbe 8, 36-43. doi: 10.1016/j.chom.2010.06.003

Winter, S. E., Thiennimitr, P., Winter, M. G., Butler, B. P., Huseby, D. L., Crawford, R. W., et al. (2010b). Gut inflammation provides a respiratory electron acceptor for Salmonella. Nature 467, 426-429. doi: 10.1038/nature09415

Wong, C. E., Sad, S., and Coombes, B. K. (2009). Salmonella enterica serovar Typhimurium exploits Toll-like receptor signaling during the host-pathogen interaction. Infect. Immun. 77, 4750-4760. doi: 10.1128/IAI.00545-09 
Wood, M. W., Jones, M. A., Watson, P. R., Hedges, S., Wallis, T. S., and Galyov, E. E. (1998). Identification of a pathogenicity island required for Salmonella enteropathogenicity. Mol. Microbiol. 29, 883-891. doi: 10.1046/j.1365-2958.1998.00984.x

Worley, M. J., Ching, K. H. L., and Heffron, F. (2000). Salmonella SsrB activates a global regulon of horizontally acquired genes. Mol. Microbiol. 36, 749-761. doi: 10.1046/j.1365-2958.2000.01902.x

Wray, G. A. (2007). The evolutionary significance of cis -regulatory mutations. Nat. Rev. Genet. 8, 206-216. doi: 10.1038/nrg2063

Zaneveld, J., Turnbaugh, P. J., Lozupone, C., Ley, R. E., Gordon, J. I., and Knight, R. (2008). Host-bacterial coevolution and the search for new drug targets. Curr. Opin. Chem. Biol. 12, 109-114. doi: 10.1016/j.cbpa.2008. 01.015

Zarepour, M., Bhullar, K., Montero, M., Ma, C., Huang, T., Velcich, A., et al. (2013). The mucin Muc2 limits pathogen burdens and epithelial barrier dysfunction during Salmonella enterica serovar Typhimurium colitis. Infect. Immun. 81, 3672-3683. doi: 10.1128/IAI. 00854-13
Zwir, I., Latifi, T., Perez, J. C., Huang, H., and Groisman, E. A. (2012). The promoter architectural landscape of the Salmonella PhoP regulon. Mol. Microbiol. 84, 463-485. doi: 10.1111/j.1365-2958.2012.08036.x

Zwir, I., Shin, D., Kato, A., Nishino, K., Latifi, T., Solomon, F., et al. (2005). Dissecting the PhoP regulatory network of Escherichia coli and Salmonella enterica. Proc. Natl. Acad. Sci. U.S.A. 102, 2862-2867. doi: $10.1073 /$ pnas.0408238102

Conflict of Interest Statement: The authors declare that the research was conducted in the absence of any commercial or financial relationships that could be construed as a potential conflict of interest.

Copyright (C) 2017 Ilyas, Tsai and Coombes. This is an open-access article distributed under the terms of the Creative Commons Attribution License (CC BY). The use, distribution or reproduction in other forums is permitted, provided the original author(s) or licensor are credited and that the original publication in this journal is cited, in accordance with accepted academic practice. No use, distribution or reproduction is permitted which does not comply with these terms. 